University of Nebraska - Lincoln

DigitalCommons@University of Nebraska - Lincoln

\title{
Complementarity of ResourceSat-1 AWiFS and Landsat TM/ETM+ sensors
}

\author{
S.N. Goward \\ University of Maryland, sgoward@umd.edu \\ G. Chander \\ US Geological Survey, gchander@usgs.gov \\ M. Pagnutti \\ Stennis Space Center, mary.pagnutti@ssc.nasa.gov
}

A. Marx

University of Maryland, marxaj@umd.edu

R. Ryan

Stennis Space Center

See next page for additional authors

Follow this and additional works at: https://digitalcommons.unl.edu/usgsstaffpub

Goward, S.N.; Chander, G.; Pagnutti, M.; Marx, A.; Ryan, R.; Thomas, N.; and Tetrault, R., "Complementarity of ResourceSat-1 AWiFS and Landsat TM/ETM+ sensors" (2012). USGS Staff -- Published Research. 523. https://digitalcommons.unl.edu/usgsstaffpub/523

This Article is brought to you for free and open access by the US Geological Survey at DigitalCommons@University of Nebraska - Lincoln. It has been accepted for inclusion in USGS Staff -- Published Research by an authorized administrator of DigitalCommons@University of Nebraska - Lincoln. 


\section{Authors}

S.N. Goward, G. Chander, M. Pagnutti, A. Marx, R. Ryan, N. Thomas, and R. Tetrault 


\title{
Complementarity of ResourceSat-1 AWiFS and Landsat TM/ETM + sensors
}

\author{
S.N. Goward ${ }^{\text {a,* }}$, G. Chander ${ }^{\text {b }}$, M. Pagnutti ${ }^{c}$, A. Marx ${ }^{\text {a }}$, R. Ryan ${ }^{c}$, N. Thomas ${ }^{\text {a }}$, R. Tetrault ${ }^{\mathrm{d}}$ \\ a Department of Geography, University of Maryland, College Park MD 20742, United States \\ b SGT Inc., US Geological Survey (USGS) Earth Resources Observation and Science (EROS) Center, Sioux Falls, SD, 57198, United States \\ c $I 2 R$ Corp, Stennis Space Center, MS, 39529, United States \\ ${ }^{\mathrm{d}}$ US Department of Agriculture, Washington DC, United States
}

\section{A R T I C L E I N F O}

\section{Article history:}

Received 18 November 2011

Received in revised form 29 February 2012

Accepted 2 March 2012

Available online 5 April 2012

\section{Keywords:}

ResourceSat-1 AWiFS

Landsat Thematic Mapper and Thematic

Mapper Plus

Geometry

Radiometry

BRDF

Agriculture

Forests

CEOS MODRES constellation

\begin{abstract}
A B S T R A C T
Considerable interest has been given to forming an international collaboration to develop a virtual moderate spatial resolution land observation constellation through aggregation of data sets from comparable national observatories such as the US Landsat, the Indian ResourceSat and related systems. This study explores the complementarity of India's ResourceSat-1 Advanced Wide Field Sensor (AWiFS) with the Landsat 5 Thematic Mapper (TM) and Landsat 7 Enhanced Thematic Mapper Plus (ETM+). The analysis focuses on the comparative radiometry, geometry, and spectral properties of the two sensors. Two applied assessments of these data are also explored to examine the strengths and limitations of these alternate sources of moderate resolution land imagery with specific application domains. There are significant technical differences in these imaging systems including spectral band response, pixel dimensions, swath width, and radiometric resolution which produce differences in observation data sets. None of these differences was found to strongly limit comparable analyses in agricultural and forestry applications. Overall, we found that the AWiFS and Landsat $\mathrm{TM} / \mathrm{ETM}+$ imagery are comparable and in some ways complementary, particularly with respect to temporal repeat frequency. We have found that there are limits to our understanding of the AWiFS performance, for example, multi-camera design and stability of radiometric calibration over time, that leave some uncertainty that has been better addressed for Landsat through the Image Assessment System and related cross-sensor calibration studies. Such work still needs to be undertaken for AWiFS and similar observatories that may play roles in the Global Earth Observation System of Systems Land Surface Imaging Constellation.
\end{abstract}

(c) 2012 Elsevier Inc. All rights reserved.

\section{Introduction}

The land science community is increasingly interested in moderate spatial resolution (MODRES: $10-100 \mathrm{~m}$ ) satellite remotely sensed observations as a primary source of land cover dynamics information (Goward et al., 2009, 2011). Landsat established this type of land observatory when the first satellite was launched in 1972. Landsat to this day continues to acquire systematic, within-year and between-year multispectral observations that support analyses of local to global scale land cover change. Use of Landsat to evaluate and monitor land dynamics has recently been strongly advanced by the US Geological Survey's (USGS) decision to provide no-cost access to the US Landsat archive held at the USGS Earth Resources Observation and Science (EROS) Center in Sioux Falls, South Dakota.

The aging of current US Landsat observatories, Landsat 5 and Landsat 7, along with painfully slow progress toward deployment of the next-generation Landsat Data Continuity Mission (LDCM) has begun to undermine applied science use of Landsat, particularly in

\footnotetext{
* Corresponding author. Tel.: +1 3014052770.

E-mail address: sgoward@umd.edu (S.N. Goward).
}

the US. The concerns are whether applied sciences, currently dependent on Landsat data, can continue in the absence of one or more Landsat observatories.

Landsat 5 (L5), originally planned for a 3 year mission life, is now in its 27th year of service. Landsat 7 (L7), currently in its 12th year of operation, suffered a failure of the scanline corrector (SLC) mirror in 2003, which has harmed many uses of these data. Landsat 8 (LDCM) is currently not planned for launch until the 15 January 2013 to 15 February 2013 timeframe. The US Department of Agriculture (USDA) switched to a multi-platform approach in 2008, including the use of ResourceSat-1 AWiFS data because of these concerns.

Several countries have placed in orbit satellite sensors that are at least potentially complementary to the Landsat observatory. These include the French Satellite Pour l'Observation de la Terre (SPOT) and the Indian Remote Sensing (IRS) satellite begun in the 1980s, the Japanese Advanced Land Observing Satellite (ALOS) and the Disaster Monitoring Constellation (DMC) (Goward et al., 2009). Furthermore China, in conjunction with Brazil, has flown the China-Brazil Earth Resources Satellite (CBERS) and has flown a series of Huan jing ( $\mathrm{HJ}$ ) satellites also known as environmental satellites. All of these international activities have led the Committee on Earth Observation Satellites (CEOS) and the Group on Earth Observations (GEO) to formulate a 
working group on Land Surface Imaging (LSI) Constellation (http:// www.ceos.org/).

Despite the increasing range of international land observatories, there are in fact few MODRES land observatories that meet the high standards that Landsat established to monitor the Earth's land areas. The combination of:

- a systematic acquisition strategy

- long-term global archive (federally supported),

- visible, near infrared, shortwave infrared and thermal infrared spectral measurements

- well-calibrated geometry and radiometry

converges to meet the fundamental requirements of many land studies including Land Cover Land Use Change (LCLUC), agriculture, forest dynamics, fresh water resources and urbanization.

\subsection{Landsat data gap study team}

In 2003 - after the L7 SLC failed - the USGS and NASA formed a scientific-technical Data Gap Study Team (DGST) to assess what other international assets would be available to compliment or replace the potentially missing land observations in the US national archive (Chander \& Stensaas, 2008). After 2 years of deliberation, this team concluded that only the China-Brazil CBERS mission and the IRS AWiFS sensor might be suited as substitutes for Landsat observations. One of the tightest constraints the team identified was the need for at least one shortwave infrared (SWIR) spectral band in the measurements. One of the largest remaining uncertainties is whether the collection of a systematic global observation set would be possible with either observatory.

Since 2005 only limited progress beyond the DGST findings has been accomplished either technically or internationally, concerning use of the AWiFS or CBERS as a compliment to the Landsat TM/ETM+ (Chander et al., 2008). Recently NASA Earth Science Program managers (LCLUC, Ecosystems and Applied Science) decided to fund a further detailed assessment of AWiFS through the auspices of the USGS EROS, NASA Stennis Space Center, and University of Maryland (UMD) Geography Department. This report summarizes the outcome of these studies.

\section{Comparison of ResourceSat-1 AWiFS and Landsat TM/ETM+ technical specifications}

While the AWiFS camera modules collect data similar to Landsat, there are several significant differences between the two sensor systems. First, the Landsat TM/ETM+ is a traditional optical-mechanical multispectral scanner in which all spectral bands are acquired nearly simultaneously. The AWiFS sensor package consists of two separate camera modules, each of which has four linear array cameras (Fig. 1). Interestingly, The IRS team selected to use Landsat TM band number nomenclature for both their Linear Imaging Self Scanner (LISS) and AWiFS cameras (National Remote Sensing Agency, 2003) (Table 1). The TM/ETM+ instrument nominally acquires 7 spectral bands versus AWiFS 4 spectral bands. The blue (B1), second SWIR (B7), and thermal infra-red (TIR) bands (B6) are not observed with the AWiFS sensor (Table 2).

\subsection{Radiometry}

Other differences between the two sensor systems are found primary with geometry and radiometry (Table 2 ). The AWiFS produces lower ground spatial resolution (56 $\mathrm{m}$ at nadir) versus TM's $30 \mathrm{~m}$ instantaneous field of view (IFOV) at nadir. However AWiFS radiometry is acquired at 10-bits versus TM's 8-bits (National Remote Sensing Agency, 2003). The Relative spectral response (RSR) functions for the two sensors are similar although the AWiFS bands tend to be

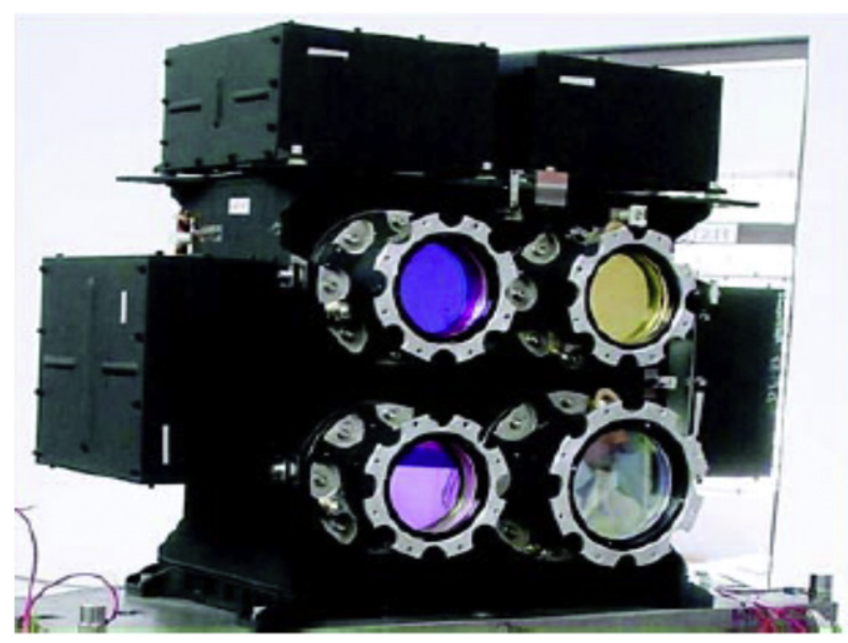

Fig. 1. Single AWiFS camera module. This is one of the two modules used to make up the full AWiFS sensor. Note that the SWIR camera (lower right) uses a larger, longer focal length lens than the other three spectral cameras.

narrower than the $\mathrm{TM} / \mathrm{ETM}+$, similar to the spectral filters in the Operational Landsat Imager (OLI) to be flown on the LDCM (Fig. 2).

\subsection{Geometry}

A primary difference between TM/ETM + and AWiFS is the wider swath of AWiFS (Fig. 3). The full AWiFS sensor consists of two separate electro-optic camera modules (AWiFS-A and AWiFS-B) mounted adjacent to each other. Each AWiFS camera module has a swath slightly more than double the Landsat TM/ETM + swath (372 km versus $180 \mathrm{~km}$ ). The full sensor two camera module system is mounted such that each camera is tilted $11.94^{\circ}$ with respect to nadir. This provides a full swath of over $730 \mathrm{~km}$ or 4 times as great as a Landsat scene. A full AWiFS image consists of four sub-images or Quads noted as A, B, C and D (Fig. 4). The Quads are acquired through forward motion of the sensor assembly in orbit.

This two camera module arrangement results in the AWiFS sensor imaging $\pm 24.3^{\circ}$ from nadir versus TM's $\pm 7.5^{\circ}$. This wider AWiFS swath significantly improves the revisit time. However, this also substantially increases off-axis imaging and therefore increases the potential for observing bidirectional reflectance distribution function (BRDF) effects from the surface and the atmosphere (Gutman, 1998; Gutman et al., 1995; Los et al., 2005). Multiple cameras also increase radiometric calibration complexity. Further, AWiFS visible near-infra-red (VNIR) cameras (B2-B4) use rectangular detectors that result in considerably different IFOVS in the across-track versus along-track directions (Table 1, Fig. 5). The SWIR spectral cameras (B5) use larger, square detectors that are compensated for by using a longer focal length lens on the camera (Table 1, Fig. 1).

\subsubsection{Orthorectification}

Both image data sets were processed to a level $1 \mathrm{~T}$ - terrain corrected or orthorectified product. Data resampling was conducted using cubic convolution. The Landsat data was resampled to $30 \mathrm{~m}$ IFOV versus the $56 \mathrm{~m}$ AWiFS (Lutes, 2005, 2006).

Table 1

Differences in the SWIR spectral camera with the visible and near infrared cameras. This difference can also be seen in Fig. 1. (Dave et al., 2006).

\begin{tabular}{lll}
\hline & Bands 2, 3, 4 & Band 5 \\
\hline Focal length & $139.5 \mathrm{~mm}$ & $181.3 \mathrm{~mm}$ \\
Detector size (cross-track) & $10 \mu \mathrm{m}$ & $13 \mu \mathrm{m}$ \\
Detector size (along-track) & $7 \mu \mathrm{m}$ & $13 \mu \mathrm{m}$ \\
Detector material & Silicon & Indium gallium arsenide \\
\hline
\end{tabular}


Table 2

Comparison of Landsat and AWiFS key characteristics. NIR = near infrared; SWIR $=$ shortwave infrared; TIR $=$ thermal infrared.

\begin{tabular}{|c|c|c|c|c|}
\hline \multirow[t]{2}{*}{ Parameter } & \multicolumn{2}{|l|}{ Landsat } & \multicolumn{2}{|l|}{ AWiFS } \\
\hline & Band & Microns & Band & Microns \\
\hline \multirow[t]{7}{*}{ Spectral } & 1 (blue) & $0.45-0.52$ & - & NA \\
\hline & 2 (green) & $0.52-0.60$ & 2 (Green) & $0.52-0.59$ \\
\hline & 3 (red) & $0.63-0.69$ & 3 (Red) & $0.62-0.68$ \\
\hline & 4 (NIR) & $0.76-0.90$ & $4(\mathrm{NIR})$ & $0.77-0.86$ \\
\hline & 5 (SWIR-1) & $1.55-1.75$ & 5 (SWIR) & $1.55-1.70$ \\
\hline & 6 (TIR) & $10.4-12.5$ & - & NA \\
\hline & 7 (SWIR-2) & $2.08-2.35$ & - & NA \\
\hline GSD & \multicolumn{2}{|c|}{30 -meter at nadir } & \multicolumn{2}{|c|}{ 56-meter at nadir } \\
\hline Quantization & \multicolumn{2}{|c|}{8 bits } & \multicolumn{2}{|c|}{$\begin{array}{l}10 \text { bits ( } 8 \text { bits from } \\
\text { USDA until 2008) }\end{array}$} \\
\hline Onboard calibration & \multicolumn{2}{|l|}{ Yes } & \multicolumn{2}{|c|}{ No } \\
\hline Revisit time & \multicolumn{2}{|l|}{16 days } & \multicolumn{2}{|l|}{5 days } \\
\hline Orbital-repeat cycle & \multicolumn{2}{|l|}{16 days } & \multicolumn{2}{|l|}{24 days } \\
\hline Orbital inclination & \multicolumn{2}{|l|}{$98.2^{\circ}$} & \multicolumn{2}{|l|}{$98.69^{\circ}$} \\
\hline Orbital period & \multicolumn{2}{|l|}{$99 \mathrm{~min}$} & \multicolumn{2}{|l|}{$101,35 \mathrm{~min}$} \\
\hline Equatorial crossing & \multicolumn{2}{|l|}{ 10:00 AM } & \multicolumn{2}{|l|}{ 10:30 AM } \\
\hline Off-axis viewing angle & \multicolumn{2}{|c|}{ Up to $7.5^{\circ}$ off nadir } & \multicolumn{2}{|c|}{ Up to $24.3^{\circ}$ off nadir } \\
\hline Altitude & \multicolumn{2}{|c|}{$705 \mathrm{~km}$} & \multicolumn{2}{|c|}{$817 \mathrm{~km}$} \\
\hline Swath & \multicolumn{2}{|l|}{185 km } & \multicolumn{2}{|c|}{$\begin{array}{l}737 \text { km (combined) } \\
\text { 2-cameras }\end{array}$} \\
\hline Architecture & \multicolumn{2}{|c|}{ Cross-track scanner } & \multicolumn{2}{|c|}{ Pushbroom } \\
\hline
\end{tabular}

\section{Data access}

\subsection{AWiFS from USDA (GeoEye)}

The ResourceSat-1 AWiFS images used in this analysis were received from the USDA Foreign Agricultural Service (FAS) Satellite
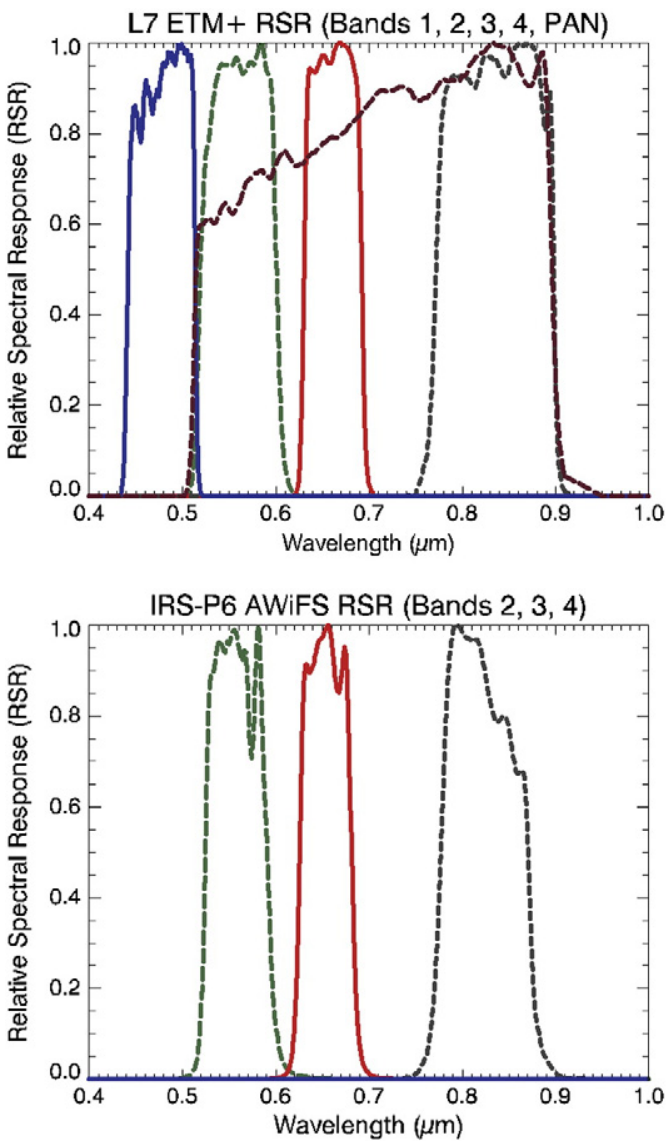

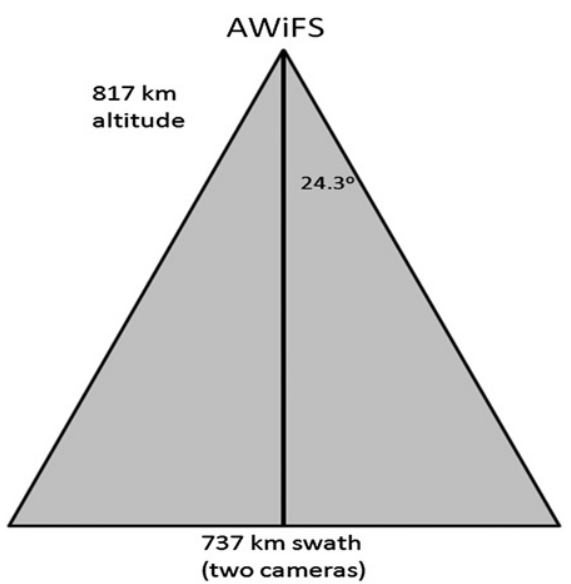

Landsat

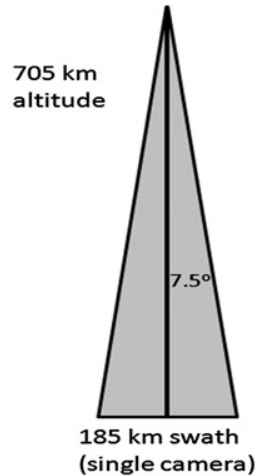

Fig. 3. AWiFS collection geometry compared to Landsat.

Imagery Archive (SIA) (Johnson, 2008). The goals of the USDA-SIA are to:

Reduce the acquisition costs over all USDA agencies

Take advantage of contracts already in place

Benefit all participants by leveraging a single USDA purchasing body.

These data were acquired under a "Tier 2" license with GeoEye, the US distributor of AWiFS data, which permits redistribution to other US Federal/Civil agencies. The USDA is the largest commercial purchaser of the AWiFS data. Imagery is purchased based on contract
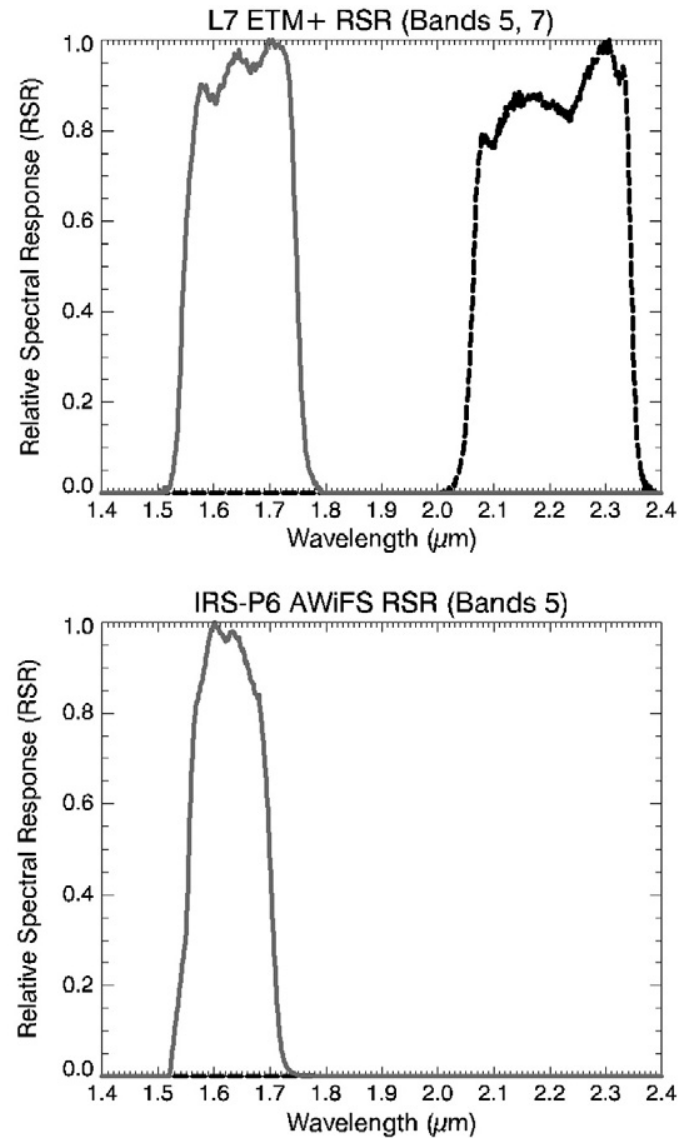

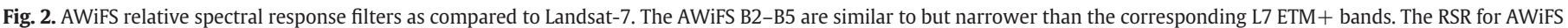

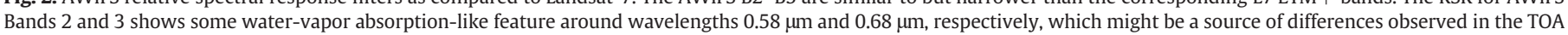
reflectance trends for both sensors. The NIR and SWIR bands differ the most compared to L7 (personal communication from ISRO). 

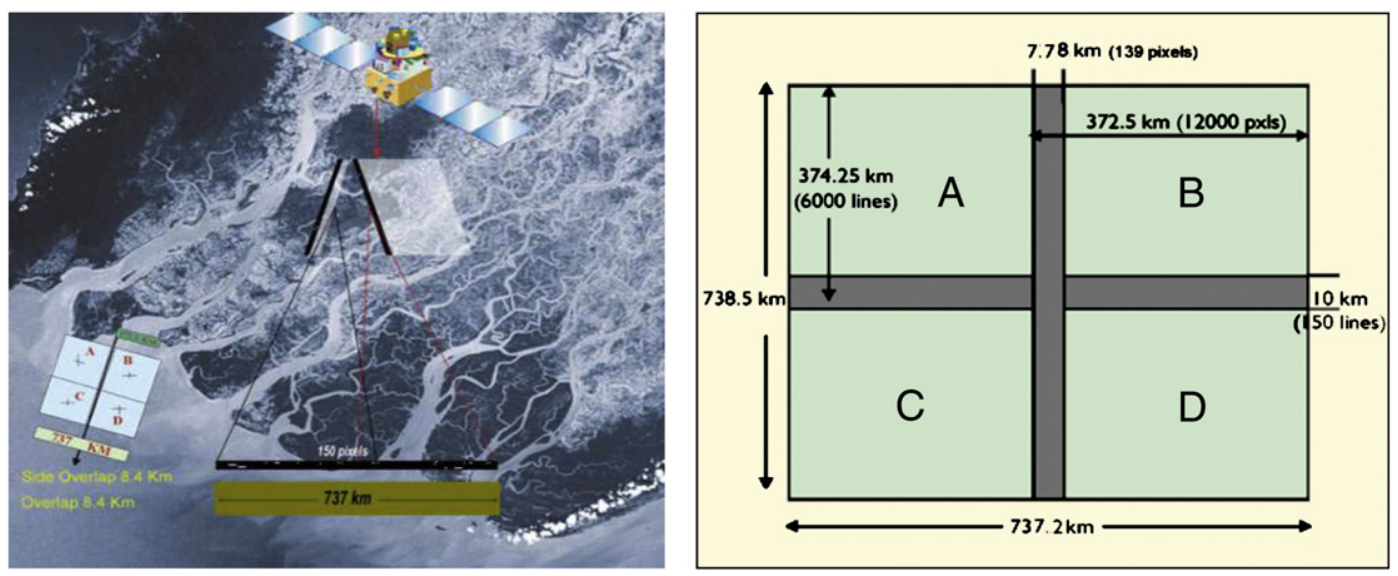

Fig. 4. AWiFS camera arrangement and associated scene quad.
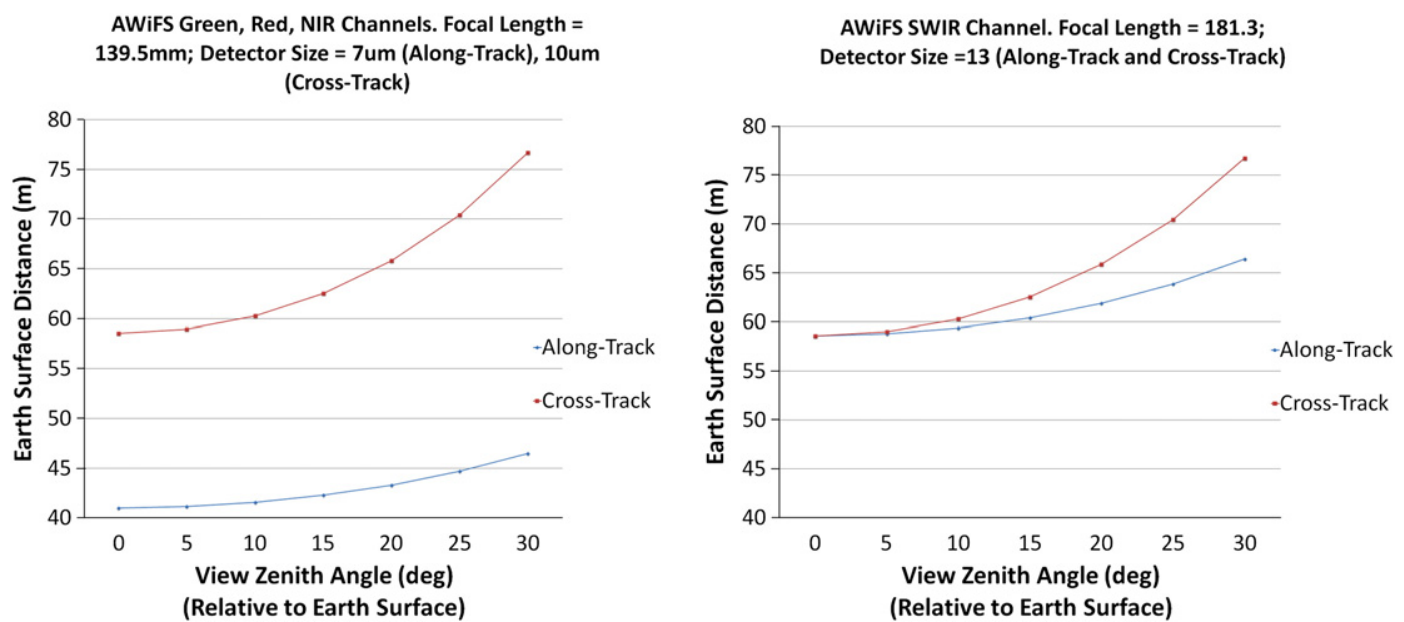

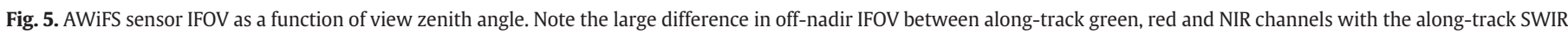
channel. These calculations do not include the amount of time the signal is integrated.

specifications, including delivery on time ( 5 days after acquisition date for North America; 10 days for other areas with less than $50 \%$ cloud cover). The USDA AWiFS acquisitions began in 2004 and continued until 2010. Prior to 2008, the USDA requested only 8-bit AWiFS data but in 2008 switched to native 10-bit radiometric resolution.

\subsection{Landsat TM/ETM + from USGS EROS}

The Landsat data archive at USGSEROS Center holds an unequaled 39-year record of the Earth's surface (http://landsat.usgs.gov). Users access the Landsat archive via EarthExplorer (http://earthexplorer. usgs.gov) or Global Visualization Viewer (GloVis - http://glovis. usgs.gov). The USGS opened the Landsat archive to users at no cost via the Internet in October 2008. ${ }^{1}$ Imagery provided at no cost is only available in a single data processing recipe (Table 3 ). All the Landsat scenes used in this study come from the USGS EROS Landsat archive.

\section{Image data analysis and comparisons}

\subsection{On-orbit geometric accuracy assessment}

The L7 ETM + Image Assessment System (IAS) (Storey et al., 1999) is responsible for offline assessment of image quality to ensure

\footnotetext{
${ }^{1}$ In less than 2 years, by August 2010, three million Landsat images have been distributed to the remote sensing user community.
}

compliance with the radiometric and geometric requirements of the L7 satellite and the ETM + sensor throughout the mission (Lee et al., 2004; Storey \& Choate, 2000). This automatic image assessment approach was leveraged to perform image-to-image (I2I) and band-toband (B2B) geometry assessments.

\subsubsection{Image-to-image (I2I) assessment}

The I2I assessment is usually performed to compare the relative accuracy between two images. Conceptually, one image is selected as the reference and the other as the search image. The ground coordinates of clearly recognizable features from the reference image are compared with the corresponding coordinates obtained from the search image. In practice, a single band from the reference image is compared with the equivalent band from the search image. The comparison is based on cross-correlation between uniformly selected points across the image. Plotting the points measured between the two images helps assess any systematic bias or higher order distortion within the search image.

The reference dataset used in this analysis is the $30 \mathrm{~m}$ Global Land Survey 2000 (GLS2000) dataset (Gutman et al., 2008). This is a continuous orthorectified mosaic of Landsat imagery covering all areas of the world (http://glovis.usgs.gov/). The GLS2000 data have already been widely applied to science questions and been extensively tested within the USGS and it has a reported accuracy of less than $30 \mathrm{~m}$ root mean square error (RMSE) within the Contiguous United States (CONUS). 
Table 3

Standard AWiFS and Landsat level 1T (terrain-corrected) product specifications.

\begin{tabular}{|c|c|c|}
\hline & L7 ETM+ and L5 TM sensor & IRS-P6 AWiFS sensor \\
\hline Product type & Level 1T (terrain corrected) SRTM NED, etc. & Level 1T (terrain corrected) USGS NED within the US, SRTM outside US. \\
\hline Output format & GeoTIFF & GeoTIFF \\
\hline Pixel size & $\begin{array}{l}15 \mathrm{~m} \text { panchromatic - Band } 8 \text {, } \\
30 \mathrm{~m} \text { VIS-SWIR - Bands } 1-5 \text { and } 7 \text {, } \\
60 \mathrm{~m} \text { TIR Band-6 }\end{array}$ & 56 m VIS-SWIR - Bands 2-5 \\
\hline Resampling method & Cubic Convolution (CC) & Cubic convolution (CC) \\
\hline Map projection & $\begin{array}{l}\text { Universal transverse mercator (UTM) } \\
\text { Polar stereographic for Antarctica }\end{array}$ & Lambert conformal conic projection (LCC) \\
\hline Image orientation & Map (north up) & Map (north up) \\
\hline Distribution & File transfer protocol (FTP) download only & File transfer protocol (FTP) and CD \\
\hline
\end{tabular}

Table 4

Mean, standard deviation, and RMSE for I2I results over Sonoran and RVP with respect to GLS2000 dataset.

\begin{tabular}{|c|c|c|c|c|c|c|c|c|c|}
\hline \multirow[t]{2}{*}{ Sonoran } & \multicolumn{2}{|c|}{ Pixels } & \multicolumn{2}{|c|}{ Meters } & \multirow[t]{2}{*}{ RVPN } & \multicolumn{2}{|c|}{ Pixels } & \multicolumn{2}{|c|}{ Meters } \\
\hline & Line & Sample & Line & Sample & & Line & Sample & Line & Sample \\
\hline Mean & 0.48 & 0.18 & 26.69 & 10.25 & Mean & 0.36 & 0.30 & 20.15 & 16.92 \\
\hline Standard deviation & 0.34 & 0.38 & 18.82 & 21.00 & Standard deviation & 0.15 & 0.22 & 8.18 & 12.56 \\
\hline RMSE & 0.60 & 0.56 & 33.65 & 31.63 & RMSE & 0.41 & 0.40 & 22.87 & 22.33 \\
\hline
\end{tabular}

Since the AWiFS images cover a much larger area $\left(500,000 \mathrm{~km}^{2}\right)$ than a single GLS2000 product $\left(31,000 \mathrm{~km}^{2}\right)$, a mosaic of GLS2000 scenes was created. The native projection of the AWiFS scenes is Lambert Conformal Conic (LCC) (datum WGS84) (Table 3). For the I2I comparison, the AWiFS images were re-projected to UTM to match the GLS2000 Landsat data. The GLS2000 data were mosaicked and resampled to $56 \mathrm{~m}$ to match the resolution of AWiFS data. The AWiFS Landsat green band was used based on 70-100 correlated points. A total of 33 AWiFS scenes over Railroad Valley Playa, NV (RVPN), and 22 AWiFS scenes over the Sonoran Desert, AZ were processed for comparison to the GLS2000 data.

Vector registration residuals between AWiFS and GLS2000 mosaics were produced for the Sonoran and RVPN test sites (Table 4). The results indicate that the AWiFS green band data falls consistently within 1 pixel $(56 \mathrm{~m})$ of the Landsat aggregated $56 \mathrm{~m}$ green band data. The mean, standard deviation and RMSE along both sample and line direction indicate the same result (Table 4). The mean displacement (distance) between the reference data and AWiFS was less than half a pixel and the standard deviation of the displacement across all the scenes was found to be less than 0.4 pixels. These low mean values indicate that the AWiFS VNIR products are internally consistent. The RMSE of the displacement across all the scenes are found to be less than 0.6 . The analysis also reveals a slight trend of increasing error from the years 2006 to 2009 (from 0.38 pixels to 0.68 pixels). Since the trend is very small (within 1 pixel), it is difficult to make any specific conclusion regarding increasing misregistration. Similar analyses for the SWIR band show larger deviations, up to 2 pixels, particularly at the edges of the AWiFS scenes. Lutes (2005) observes the same trend suggesting errors associated with physical camera parameters including radial lens distortion. Because the SWIR camera uses a different focal length and therefore larger lens this is a likely cause of the registration differences between VNIR and SWIR imagery (Fig. 1).

\subsubsection{Band-to-band (B2B) assessment}

The B2B assessment provides a measure of the geometric alignment of the individual multispectral bands with each other within a given AWiFS scene. Overall, the B2B process uses the same concepts as the I2I process but in this case, the individual bands of a multispectral image are tested against each other. The B2B assessment was determined at both the RVPN and Sonoran Desert test sites, as representative of each year of study (2006-2009).
Results of this analysis indicate that B2B registration between the VNIR bands is generally good and equivalent between the bands (Table 5). The vector residuals for the SWIR spectral band indicate larger errors, on the order of 2 pixels suggesting mis-alignment in the SWIR band as compared to the VNIR bands. This supports the results noted in the I2I analysis again suggesting a difference in the SWIR camera. The differences in VNIR versus SWIR registration may be possible to adjust, as noted by Lutes (2005).

\subsection{Radiometry}

\subsubsection{AWiFS camera $A$ compared to camera $B$}

The relative radiometric performance of the two AWiFS camera modules was assessed. To compare the radiometric calibration gain and offset between the two camera modules we utilized several sets of 4-quad AWiFS scenes. Each scene contains an overlap area approximately $7.8 \mathrm{~km}$ wide (139 pixels) acquired by both camera modules at the same time (Fig. 4).

Two different approaches were taken to compare the radiometric calibration between the two cameras. In the first approach, radiometrically calibrated pixels from Quads A and B (or alternatively C and D) were geo-referenced, and mapped to each other to create a 1 to 1 pixel correspondence between the two cameras. The pixel values were then plotted against each other. Perfect relative radiometry between camera modules would yield a straight line through the origin, with a slope of 1 . In the second approach, 50 pixel averages were used as the basis of comparison instead of a single pixel. Pixel averaging increases the signal-to-noise in the calculation and as a result should

Table 5

B2B analysis results from Sonoran and RVPN acquisitions.

\begin{tabular}{|c|c|c|c|c|c|c|c|c|}
\hline \multirow{3}{*}{$\begin{array}{l}\text { Band } \\
\# \mathrm{~s}\end{array}$} & \multicolumn{4}{|l|}{ Sonoran } & \multicolumn{4}{|l|}{ RVPN } \\
\hline & \multicolumn{2}{|c|}{ Mean error } & \multicolumn{2}{|l|}{ RMSE } & \multicolumn{2}{|c|}{ Mean error } & \multicolumn{2}{|l|}{ RMSE } \\
\hline & Line & Sample & Line & Sample & Line & Sample & Line & Sample \\
\hline 2 -to-3 & 0.013 & 0.019 & 0.048 & 0.073 & 0.004 & 0.011 & 0.051 & 0.091 \\
\hline 2-to-4 & -0.013 & -0.024 & 0.086 & 0.098 & -0.044 & 0.049 & 0.087 & 0.119 \\
\hline 2-to-5 & -0.221 & 0.135 & 0.276 & 0.292 & -0.281 & -0.144 & 0.307 & 0.334 \\
\hline 3-to-4 & -0.025 & 0.014 & 0.065 & 0.066 & -0.043 & 0.052 & 0.066 & 0.076 \\
\hline 3-to-5 & -0.223 & -0.171 & 0.272 & 0.317 & -0.285 & -0.156 & 0.313 & 0.327 \\
\hline 4-to-5 & -0.205 & -0.171 & 0.262 & 0.308 & -0.259 & -0.200 & 0.301 & 0.347 \\
\hline Mean & -0.112 & -0.033 & 0.168 & 0.192 & -0.151 & -0.065 & 0.187 & 0.215 \\
\hline
\end{tabular}


produce more reliable and consistent results. Our camera A to camera B radiometric analysis found that there is a reasonably good agreement between the two AWiFS cameras (Fig. 6). The results show a linear relation between DNs from each camera. The overlap area, utilized in both of these approaches, was acquired at a Nadir viewing geometry. AWiFs imagery is provided with an absolute calibration that can be applied to Level 1 product DN values and holds for all pixels across the pushbroom array. Vicarious absolute radiometric calibrations and cross calibrations with Landsat did not show any significant flat fielding errors. Since the acquisition geometry for the two camera modules is identical within the overlap area, any radiometric inconsistencies resulting from errors in flat fielding or BRDF would be identical for each camera and would not enter into this relative radiometric assessment.

\subsubsection{AWiFS compared to L7 ETM+}

To evaluate the radiometric calibration accuracy of AWiFS, the AWiFS images were compared to near-simultaneous L7 ETM+ images. Given the careful attention that has been given to Landsat radiometry, the underlying assumption of this analysis is that the Landsat radiometry is "truth" (Chander et al., 2009; Markham et al., 2004).

Both data sets were converted to top-of-atmosphere (TOA) spectral reflectance to account for conversion from digital numbers to radiance as well as differing sensor relative response functions and solar zenith angle (Chander et al., 2009). Because of the differing orbital geometry and equatorial crossing time, the closest encounter between Landsat 7 and ResourceSat-1 is approximately 30 min (Table 2). Therefore an image pair represents an acquisition of an observed area by both the sensors acquired within $30 \mathrm{~min}$. As a result, some differences in atmospheric attenuation may still be present in this comparison.

To conduct the comparison images with high solar elevation angles were identified. Common regions of interest (ROIs) with spatial uniformity and minimal cloud cover were located. Multiple ROIs with these properties but covering a wide range of reflectance to cover the dynamic range of the instrument were identified to evaluate the relative performance of the two sensors across all reflectance levels. ROI spatial uniformity was evaluated by calculating the coefficient of variation ( $\mathrm{CoV})$, defined as the standard deviation/mean. ROIs with $\mathrm{CoV}<10 \%$ were selected for analysis.

The ratio of the spatial resolution between the two sensors is 1.87 (56/30). Hence, to get the same area covered in both the sensors the ROI size must be scaled accordingly. In this particular analysis, a $400 \times 400$ pixel ROI size was used for TM/ETM+ images and a corresponding $214 \times 214$ pixel size ROI was used for the AWiFS images. A range of bright and dark locations were selected to fully characterize each sensor's dynamic range.

The results show that the AWiFS and Landsat images are well related, with explained variance above $94 \%$ in all band pairs and above $97 \%$ in the VNIR bands (Fig. 7). There is however an offset in relations between the VNIR bands with the AWiFS recording lower reflectances, on average 0.11 less, than the Landsat TOA reflectances. There are many possible causes of these differences including the differing RSRs of the two sensors and atmospheric conditions. However neither of these explanations is confirmed by the evidence. A third possibility is that the AWiFS sensor calibration parameters do not describe the current state of the observatory. The calibration information in the AWiFS metadata originates from preflight calibration information. The images used in this comparison were acquired 3 to 5 years since launch. As with many satellite-based sensors, some sensor degradation can be experienced over time. Further evidence of this possibility is our comparison with equivalent L5 observations (Fig. 8) which show a similar offset between AWiFS and Landsat. Calibration coefficients for both L5 and L7 are up to date and in accordance with each other.

\subsubsection{AWiFS long term radiometric stability}

An initial effort to assess AWiFS long-term radiometric stability began using the observations collected for the Arizona Sonoran Desert site from June 2006 to September 2009. Unfortunately, the AWiFS data over the traditional standard CEOS reference pseudo-invariant test sites (Libya 4, Mauritania 1/2, Algeria 3, Libya 1, and Algeria 5) were not available. Previous studies, over the Sonoran (Angal et al., 2010) and other pseudo-invariant sites have demonstrated that the ETM+ sensor is extremely stable (Chander et al., 2010).

The analysis was performed using 22 cloud-free AWiFS scenes along the more dense time series of L7 data acquired from June 2006 through September 2009. Homogeneous ROIs of approximately 22 by $28 \mathrm{~km}$ extent were selected in the calibrated images. Mean target statistics were derived from sensor measurements in terms of TOA reflectance. Since only a limited number of scenes were available over these sites, the TOA reflectance trending from spectrally matching L7 ETM + bands were compared for each equivalent spectral band (Fig. 9). For each band pair a set of fitted coefficients (slope and offset) is provided to monitor the long-term stability over the test site.

The AWiFS scenes from 2006 to 2009 used in this analysis indicate a drift in the TOA reflectance trending in all the bands. The statistical

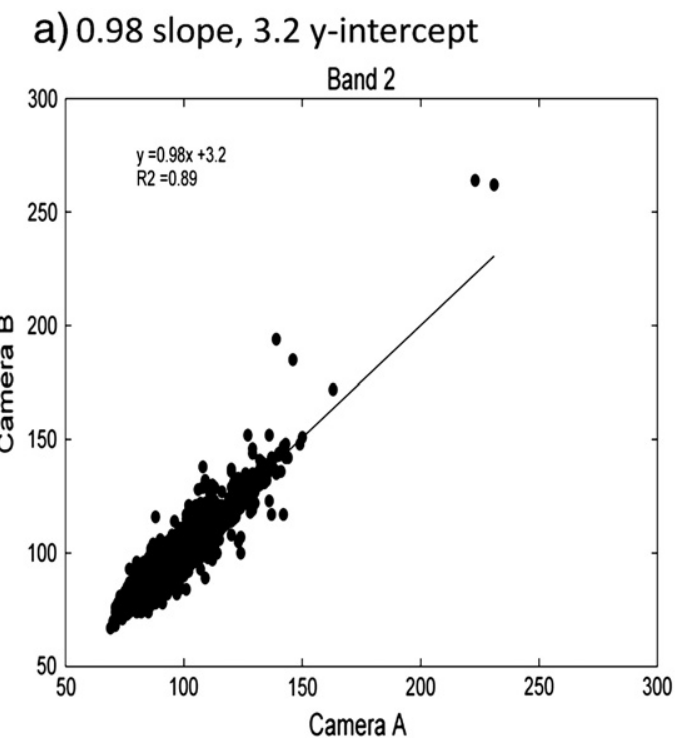

\section{b) 0.97 slope, 4.7 y intercept}

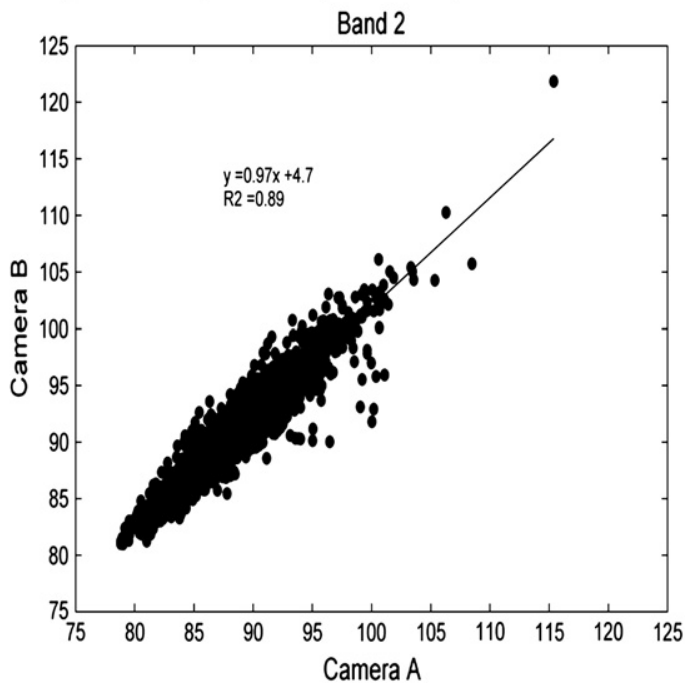

Fig. 6. Comparative scatter plots for single pixels and 50 pixel averages. 
L7 ETM+ \& IRS-P6 AWiFS TOA Reflectance, Band 2

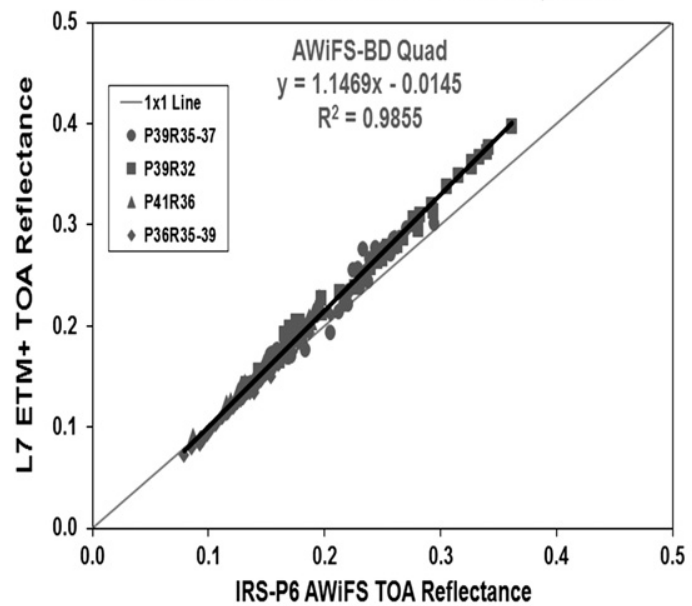

L7 ETM+ \& IRS-P6 AWiFS TOA Reflectance, Band 4

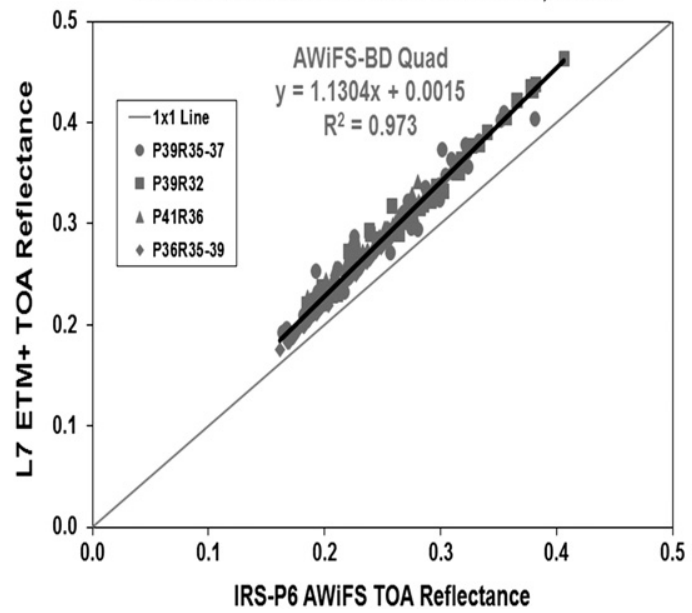

L7 ETM+ \& IRS-P6 AWiFS TOA Reflectance, Band 3

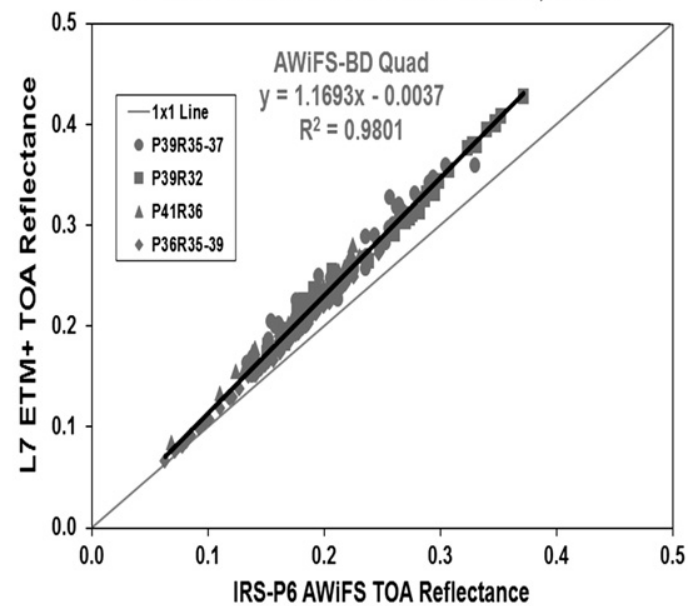

L7 ETM+ \& IRS-P6 AWiFS TOA Reflectance, Band 5

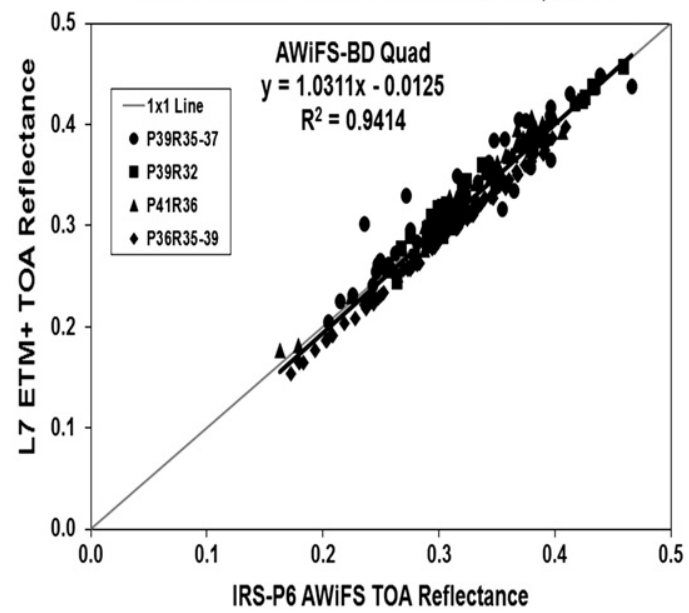

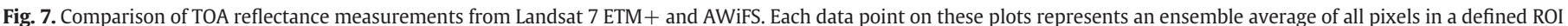
for a given day and spectral band.

T-test analysis for slope of the AWiFS TOA reflectance regression fit parameters over the Sonoran test sites confirms the long-term degradation. However, the limited number of AWiFS images (22) over the three year period makes it very difficult to perform a comprehensive assessment of the long-term stability. The team is working with GeoEye to obtain additional AWiFS data over this site to extend the preliminary assessment performed here. Preliminary results from the RVPN site also showed the consistent drift in the TOA reflectance for AWiFS.

\subsection{Impact of BRDF on AWiFS observations}

Because the AWiFS system images across $\pm 24.3^{\circ}$ from nadir, its images have the potential of being more seriously impacted by surface and atmospheric BRDF phenomena than the corresponding Landsat TM/ETM+ sensors. Further, the AWiFS camera modules are arranged such that AWiFS-A always acquires imagery in the backscatter direction while the AWiFS-B always acquires imagery in the forward scatter direction, which could cause images from camera A to have a very different reflectance measurement pattern than that recorded from camera B, even for the same land cover type (Fig. 4).

In general BRDF effects are most pronounced when imaging sensors scan within approximately $\pm 10^{\circ}$ of the solar principal plane (Norman et al., 1985). For the ResourceSat-1 observatory this occurs within $20^{\circ} \mathrm{N}-30^{\circ} \mathrm{N}$ during the summer solstice and $20^{\circ} \mathrm{S}-30^{\circ} \mathrm{S}$ during the winter solstice. To demonstrate how large the BRDF effect can be, a single AWiFS-A scene, imaging in the backscatter direction, acquired on June 25, 2008 from northern Mexico was examined. For the coarsely classified bare Earth land cover, an east to west acrossscene increase from $18 \%$ to near $25 \%$ in the B2 (green) and B3 (red) bands are observed. In B4 (NIR) the increase is from 25\%-30\%. In B5 (SWIR) the increase is from $38 \%$ to $45 \%$. A hot spot near the incident solar zenith angle $\left(19.5^{\circ}\right)$ is also evident (Fig. 10). Within this study, the focus was on US AWiFS acquisitions where the anticipated observed BRDF effects are expects to be smaller but still potentially significant.

To assess image variability introduced by the AWiFS imaging geometry we utilized a statistical model to describe a set of Earth surface BRDF correction factors that does not rely on physical parameters (Walthall et al., 1985) (Eq. 1).

$\rho\left(\theta_{s}, \theta_{v}, \varphi\right)=a_{0}+a_{1} \theta_{s}+a_{2} \theta_{v} \cos (\varphi)$

where:

$\rho \quad$ is the BRDF correction factor

$\theta_{s} \quad$ is the solar zenith (view) angle,

$\theta_{v} \quad$ is the sensor zenith (view) angle,

$\varphi \quad$ is the relative azimuth angle,

$a_{0}, a_{1}$, and $a_{2}$ are constants to be determined. 
L5 TM \& IRS-P6 AWiFS TOAReflectance, Band 2

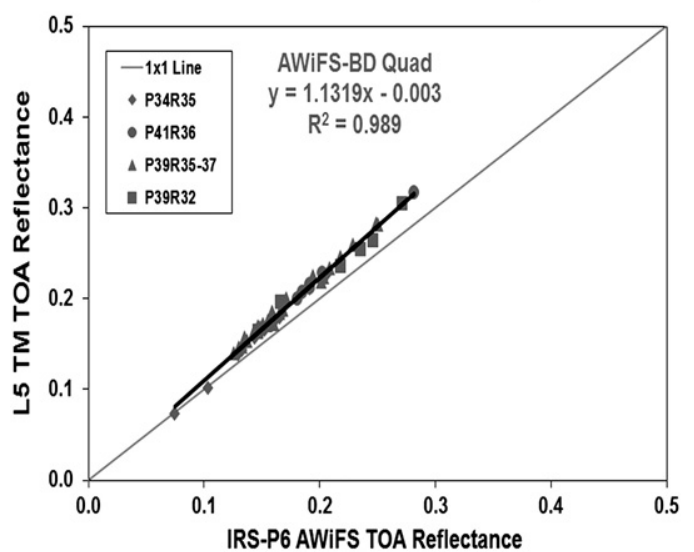

L5 TM \& IRS-P6 AWiFS TOA Reflectance, Band 4

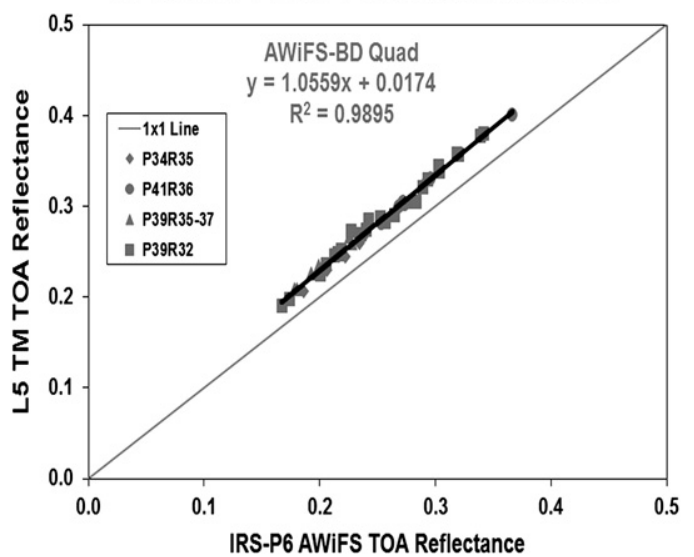

L5 TM \& IRS-P6 AWiFS TOA Reflectance, Band 3

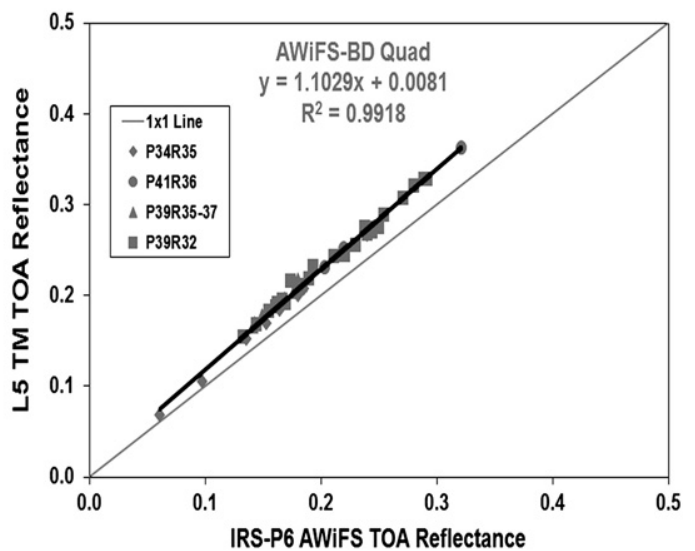

L5 TM \& IRS-P6 AWiFS TOAReflectance, Band 5

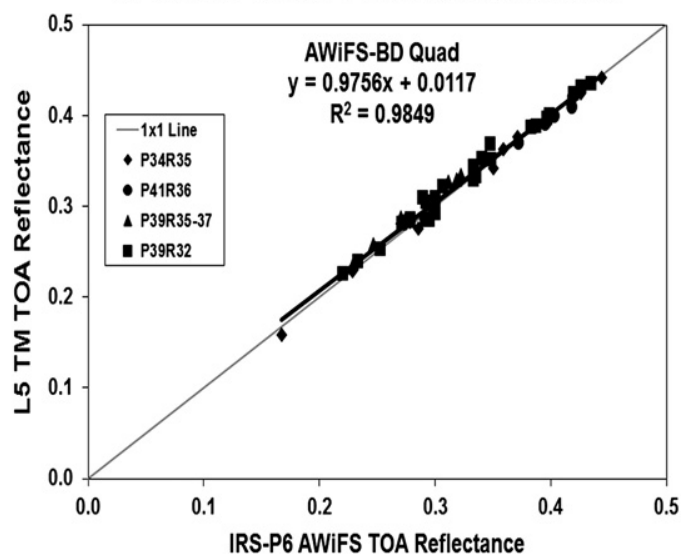

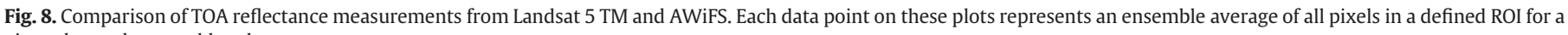
given day and spectral band.

This type of model has been widely used and expanded upon (Danaher, 2002; Danaher et al., 2001; Liang \& Strahler, 1994; Walthall et al., 1985). Danaher (2002) modified the Walthall model and tested it against Landsat data sets converted to TOA reflectance for a limited number of land cover classes. Following Danaher's approach, our assessment is based on a simple linear statistical model (Eq. 1) and uses TOA reflectance values.

Our assessment used a combination of ten AWiFS-A and B scenes acquired over predominately agricultural locations in the US and Canada for the time period January 2006 through September 2008. The scenes acquired were selected to represent a wide range of solar zenith angles from $17^{\circ}$ to $57.3^{\circ}$ Each selected scene was acquired under clear atmospheric conditions, with aerosol optical thickness values less than 0.11 at $550 \mathrm{~nm}$ to minimize atmospheric effects. The scenes varied in azimuth from $20^{\circ}$ to $54^{\circ}$ from the principal plane in the forward scatter direction and from $47^{\circ}$ to $53^{\circ}$ in the backscatter direction. All scenes were converted to TOA reflectance using Indian Space Research Organization (ISRO) provided (pre-flight) calibration coefficients.

A coarse land cover classification of woody, non-woody, bare earth and water of each scene was carried out using a supervised maximum likelihood method implemented in ENVI 4.7 based on Danaher's (2002) approach. These four classes were selected because their spectral reflectance values vary with solar and view geometry in different known ways.

Single sub-scene directional reflectance assessments were first performed on each image sub-scene prior to implementing the statistical model. Sensor zenith, sensor azimuth, solar zenith and solar azimuth angles, were assigned to each classified AWiFS pixel. The
TOA reflectance variation as a function of sensor zenith for the scene's solar geometry and each land cover class was examined. The slope of the observed relation is associated with BRDF effects present in the image for each land cover class as a whole (Fig. 11).

Because most AWiFS images within the USDA archive are single camera module acquisitions, the statistical model was implemented for each camera separately. Five thousand (5000) randomly selected pixels were chosen within each $2.5^{\circ}$ sensor zenith angular extent or "bin" across the full width of the image for each land cover class. In total each camera assessment utilized approximately two hundred fifty thousand $(250,000)$ pixels for each land cover type. A least squares fit was applied for each coarse land cover class to determine the statistical model coefficients and resulting BRDF effect. These factors varied as a function of sensor zenith angle in well behaved patterns (Fig. 12). For both AWiFS cameras, the statistical model results in general, compared well with the single scene assessments (Figs. 13 and 14). These results give confidence that the least squares fit to the modified Walthall formulation can reasonably describe the variation in reflectance found within a typical AWiFS scene for points away from the principal plane.

This assessment demonstrated a measureable AWiFS BRDF effect away from the principal plane that can be quantified and accounted for using the Walthall et al. (1985) statistical model. More complex models exist that incorporate additional components including principal plane hot spots (Lucht et al., 2000). The relatively simple modified Walthall formulation, however, is applicable to the majority of acquisitions in the USDA archive. Depending on the solar and sensor viewing geometries, BRDF effects can be significant and may need to be accounted for when utilizing multi-source data in land cover change analysis. 

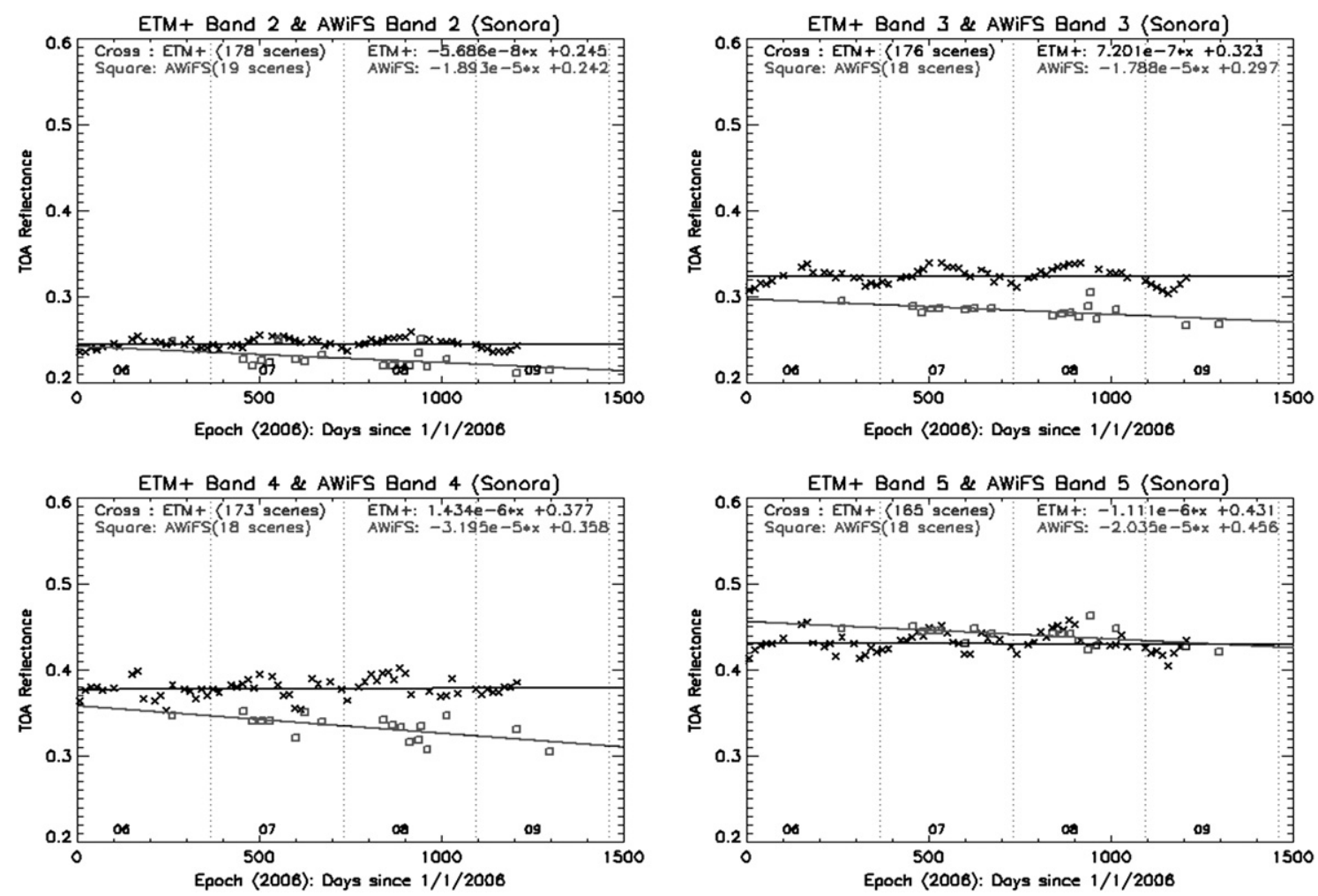

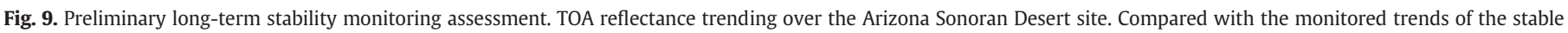

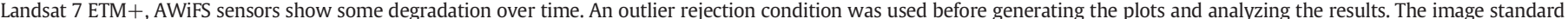

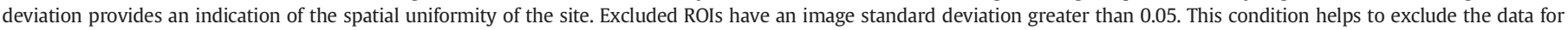
non-uniform regions. This condition is applied per band per sensor, which can result in an uneven number of images between the different bands for a given sensor.

\section{Applied use}

Technical assessment of IRS AWiFS data versus Landsat TM/ETM+ data reveals several differences in the multispectral sensors but also notes several aspects of the data sets that are similar, which therefore may make these Earth observations complementary in specific applications.

With the failure of the scan line corrector on Landsat 7 the immediate reaction of Landsat data users was to seek out other potential observation sources that could be used as replacements. The technical
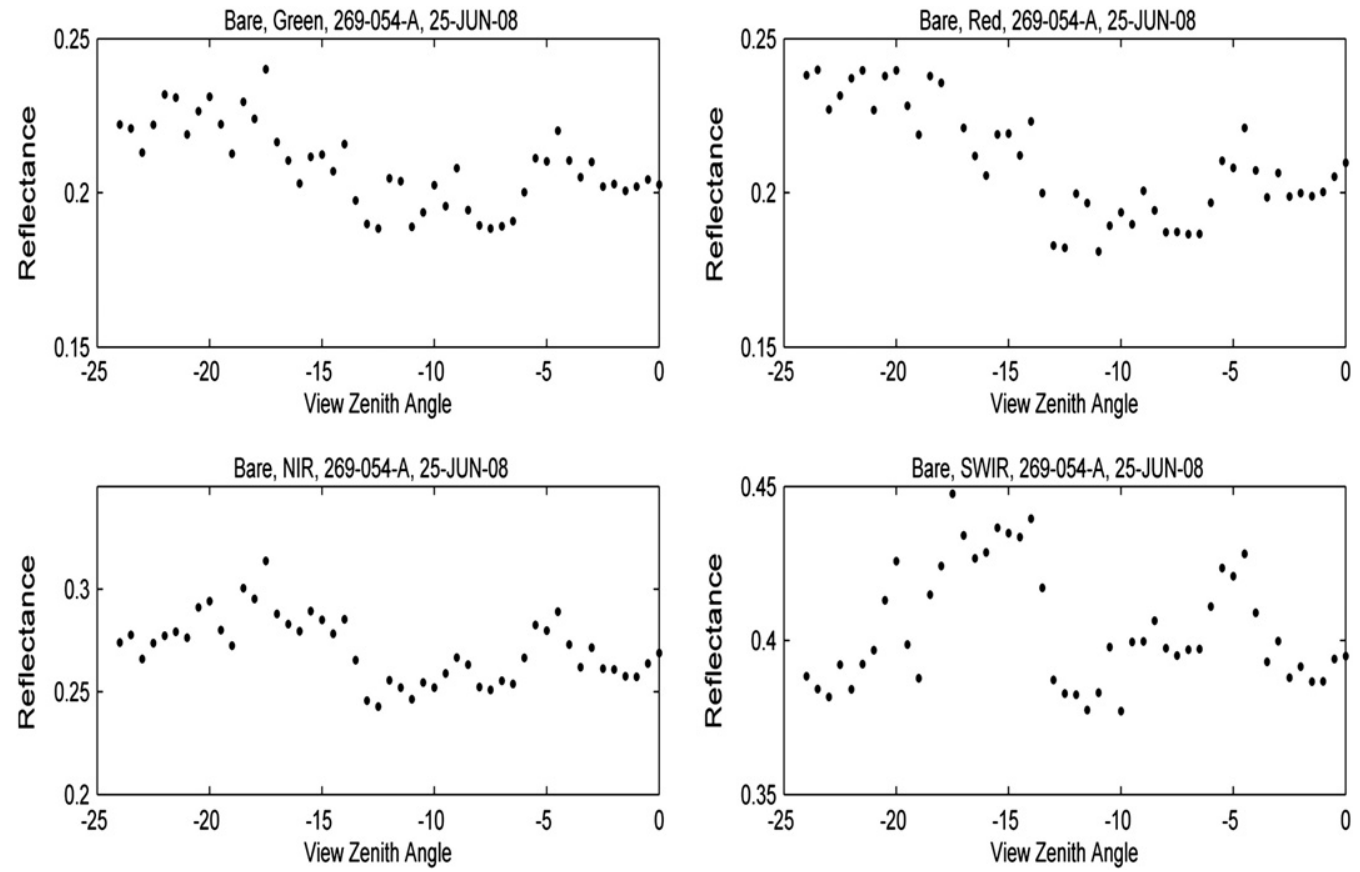

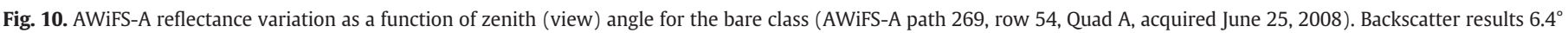
from the principal plane. Solar zenith angle is at $19.5^{\circ}$ from the principal plane. Solar zenith angle is at $19.5^{\circ}$. 

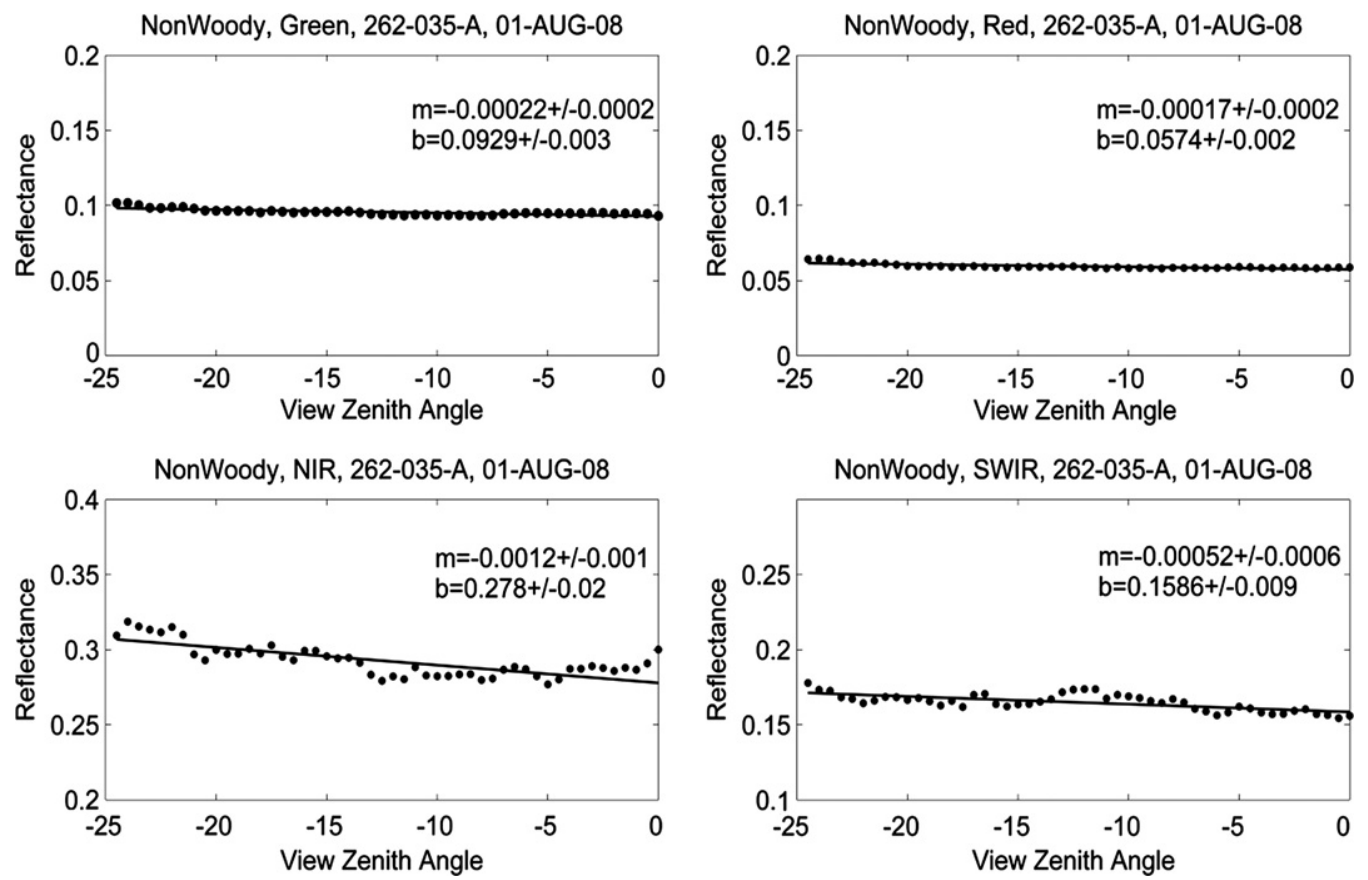

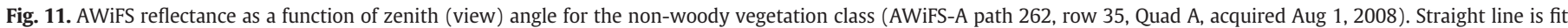
through the data.

teams suggested that AWiFS might provide such an observation source. However, access to these images proved difficult not only because of limited acquisition potential but also the commercial arrangements that ISRO had developed with selected international ground stations. As a result progress in efforts to use AWiFS as a compliment to or a replacement of Landsat TM observations has progressed only slowly.
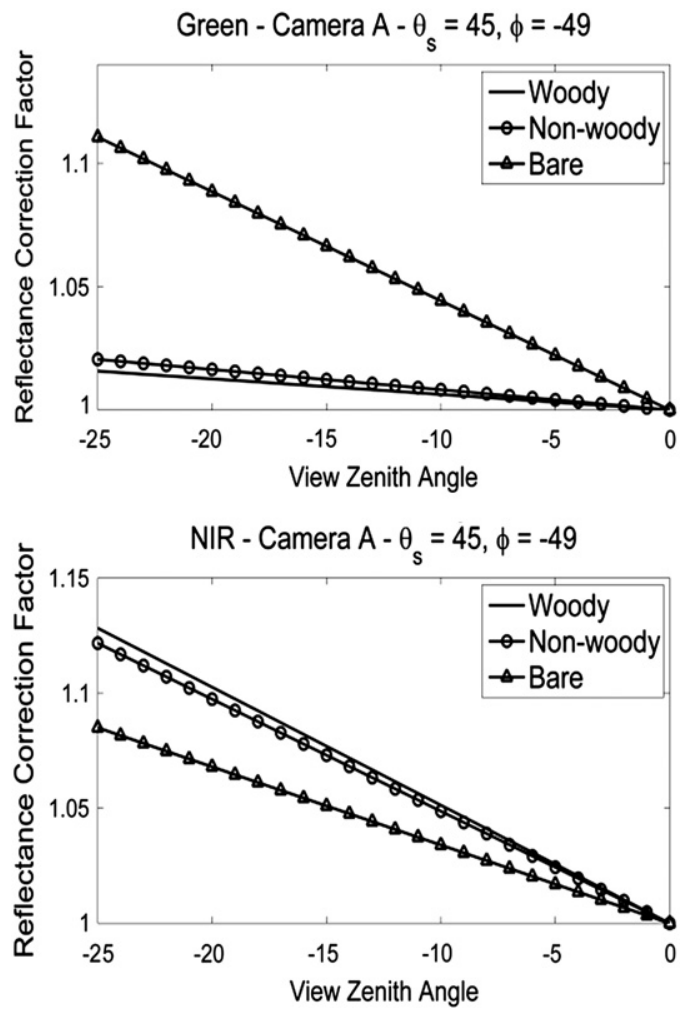

\subsection{Agriculture (USDA)}

The first major step forward in use of ResourceSat-1 AWiFS imagery in the US came from the US Department of Agriculture. The USDA is a long-time supporter of the Landsat mission and over the years has become dependent on access to satellite observations to support their US National Agricultural Statistics Service (NASS) and FAS activities.
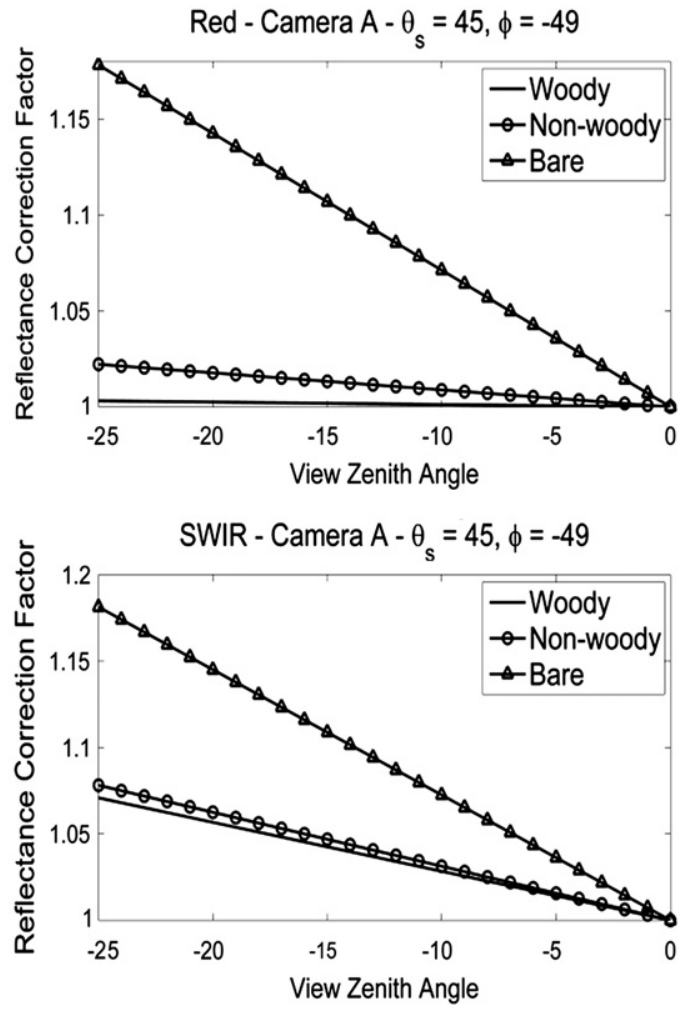

Fig. 12. Modified Walthall fit results with $\theta_{s}=45^{\circ}$ and $\phi=-49^{\circ}$ for AWiFS-A. Backscatter example is $49^{\circ}$ from the principal plane. 

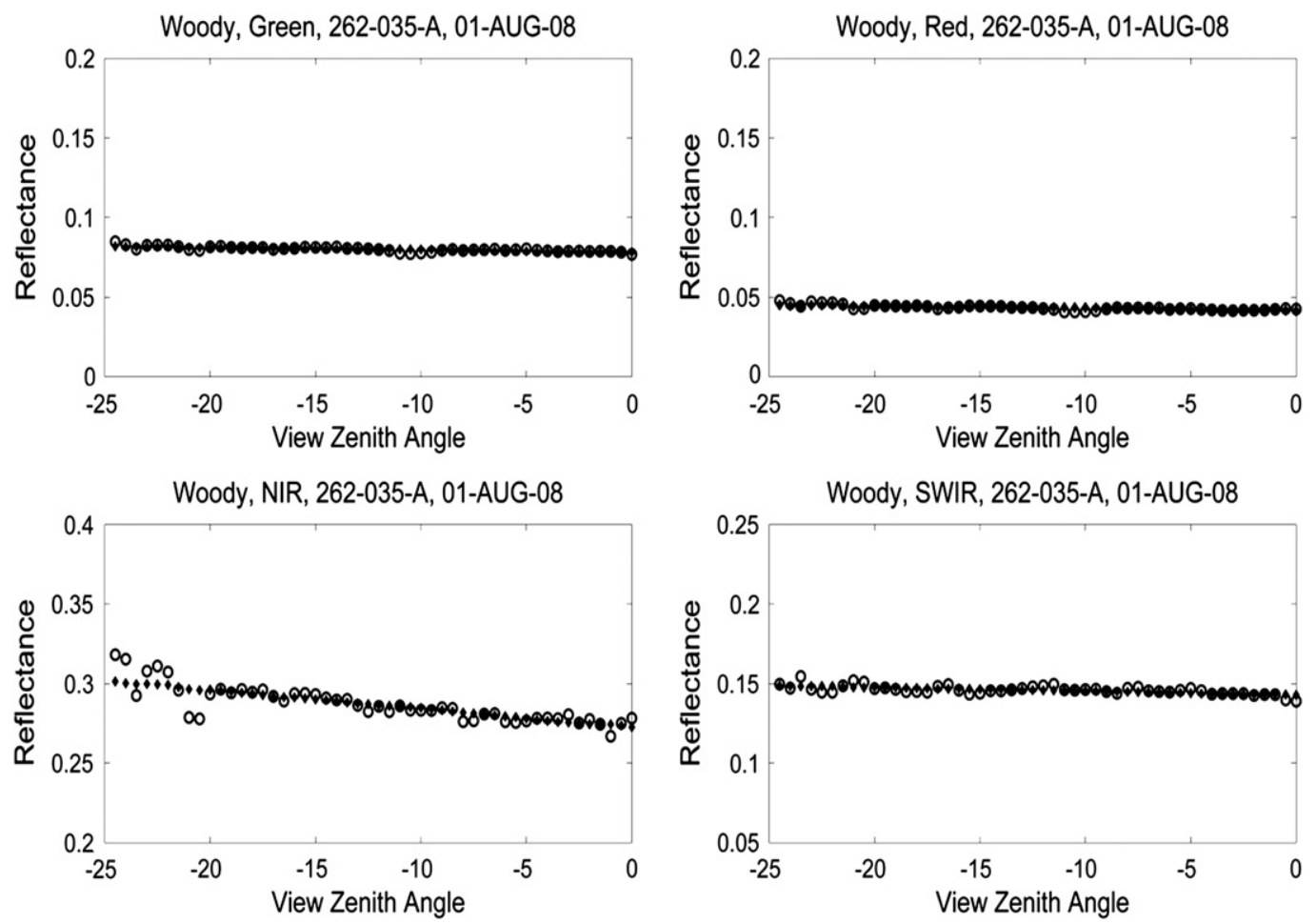

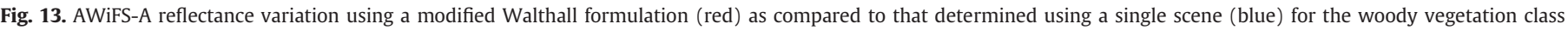
(AWiFS-A path 262, row 35, Quad A, acquired Aug 1, 2008). Backscatter results are at $47^{\circ}$ from the principal plane. Mean solar view angle is at $34.5^{\circ}$.

The reduction in the amount of available imagery due to the malfunction of the Landsat 7 sensor motivated USDA to begin to experiment with AWiFS imagery (Boryan \& Craig, 2005; Johnson, 2008). USDA developed an active relationship with GeoEye, the US supplier of IRS imagery and the commercial IRS company Antrix and began testing AWiFS datasets in 2004 (Boryan \& Craig, 2005; Johnson, 2008).

The early USDA explorations of the AWiFS imagery revealed less accurate cropland classifications than classifications from Landsat,
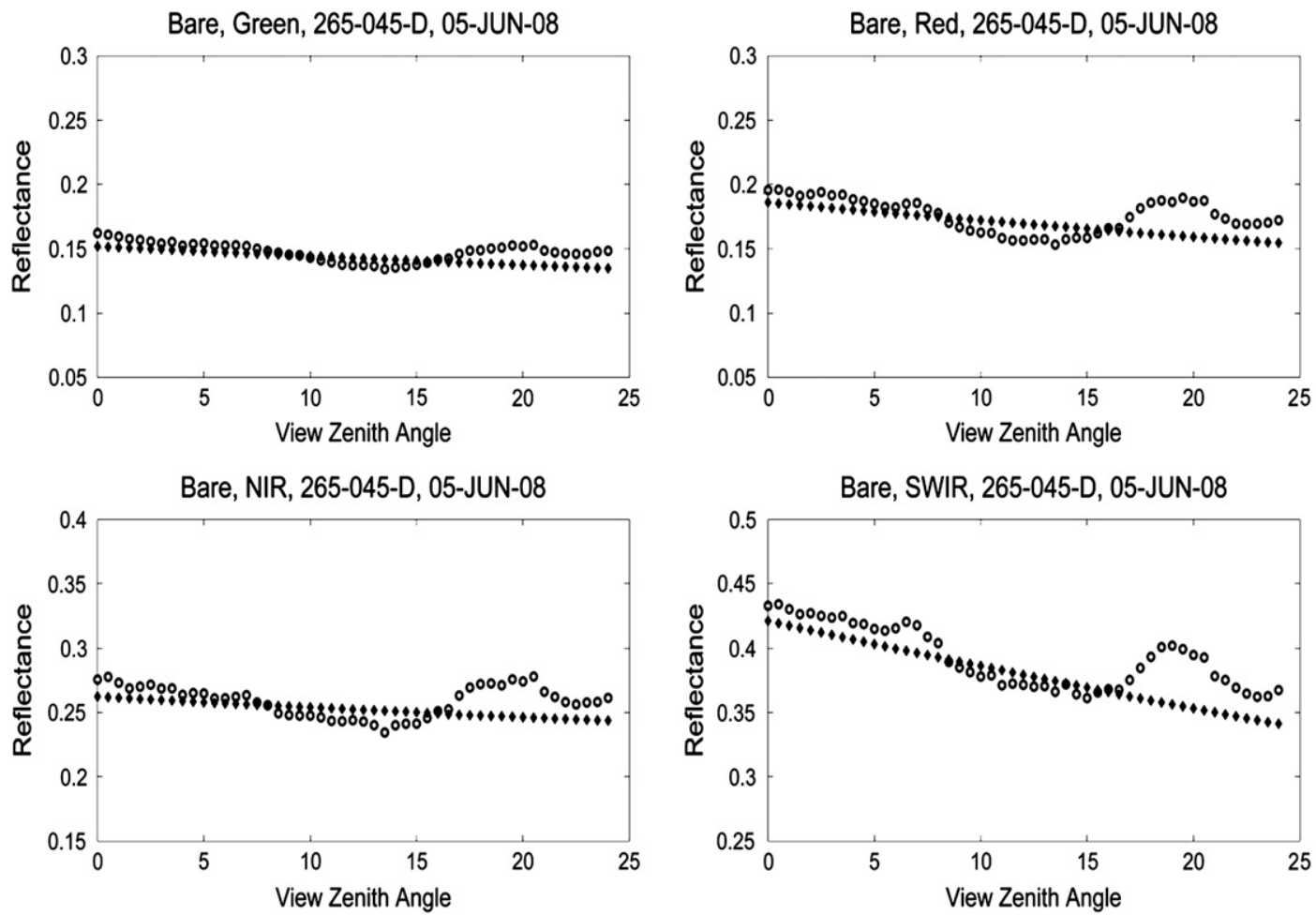

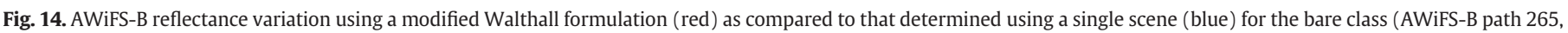
row 45, Quad D, acquired June 5, 2008). Forward scatter results area at $21.5^{\circ}$ from the principal plane. Mean solar view angle is at $17.2^{\circ}$. 
especially using single date analysis (Boryan \& Craig, 2005). When examining multi-date analysis, however, results were mixed with Landsat slightly outperforming AWiFS cropland classifications (Johnson, 2008). The USDA explorations were focused geographically on States that produce a large share of the US production of corn, soybeans, winter wheat, cotton, spring wheat and durum. These commodities are traded on US commodity markets and are the USDA's "Program Crops" (Mueller \& Seffrin, 2006). These states traditionally have large agricultural fields that may be more suitable for the larger spatial resolution of AWiFS. Explorations of smaller agricultural fields may reveal larger diminution of cropland classification accuracies.

Lower cropland classification accuracies were not an impediment to using AWiFS. In fact the AWiFS observations have some advantages, including more frequent temporal repeat frequency, large footprints, similar spectral bands to Landsat, and adequate spatial resolution for large field agriculture. These advantages, along with changes in the source of ground truth and software, spurred a major overhaul in technologies and methods in the USDA NASS Cropland Data Layer program (Mueller \& Seffrin, 2006). The Cropland Data Layer program transitioned to an operational program providing in-season estimates for decision support to USDA decision makers. Acreage estimates are delivered multiple times during the growing season, helping improve NASS estimates. Both AWiFS and Landsat imagery are used in the cropland classifications and investigations concerning the complementarity of the datasets continue.

\subsection{Forest disturbance - North American Carbon Program}

In addition to agriculture, Landsat observations are increasingly being used to evaluate US forest change statistics. Specifically, within the context of the North American Carbon Program (NACP) a team of researchers from UMD, NASA Goddard Space Flight Center (GSFC) and the US Forest Service (USFS), has been carrying out a detailed assessment of year-to-year forest disturbances to better understand North American carbon dynamics from time series stacks of Landsat observations (Goward et al., 2008). The North American Forest Dynamics (NAFD) analysis approach uses the Vegetation Change Tracker (VCT) method to identify disturbance events (Huang et al., 2010).

As with the USDA applications, the USGS is concerned that loss of the Landsat observatories could bring this type of important forest dynamics analysis to an end. With the support of NASA and USFS, the NAFD staff undertook an analysis in which appropriate AWiFS imagery was substituted in the time series stacks of selected US locations (Fig. 15). Substitution of AWiFS for Landsat scenes within the NAFD LTSS provides insight into use of alternative image sources for LCLUC products.

\subsubsection{NAFD analysis}

Under NAFD Landsat images are visually screened with optimal images selected for inclusion into a time series stack based on low cloud cover $(<10 \%)$ and an acquisition date during the summer growing season (June 15th-September 15th). All Landsat images are processed through the NASA GSFC Landsat Ecosystem Disturbance Adaptive Processing System (LEDAPS) (Huang et al., 2009; Masek et al., 2006). This processing stream includes: orthorectification; radiometric calibration and conversion to TOA reflectance and adjustment to surface reflectance (Masek et al., 2006). The VCT algorithm determines forest changes from temporal variations in forest signal, where no change from high probability forest location indicates an unchanged forest cover and deviations indicate forest cover change arising from a variety of disturbance events including harvest, fire, and conversion.

\subsubsection{AWiFS data processing}

Several AWiFS scenes were identified that overlap temporally and spatially with NAFD time series stacks. Three sites were selected as matches to NAFD with a wide range of forest types and disturbance regimes: Idaho (WRS 2 path 42 row 29); Minnesota (WRS 2 path 27 row 27); and North Carolina (WRS 2 path 16 row 35). Disturbance regimes include natural fire and storm damage in the Idaho and Minnesota sites respectively and extensive industrial forestry in the North Carolina site.

The selected AWiFS scenes were prepared for input into the LTSS by creating Landsat-like images that could be easily ingested into the VCT algorithm. The VCT utilizes each Landsat band and therefore we simulated the visible blue (Landsat B1), SWIR2 (Landsat B7), and thermal bands (Landsat B6) from the existing AWiFS Bands 2, 3, 4, and 5 for input into the automated forest disturbance detection procedures. ${ }^{2}$ For this simulation, the AWiFS bands were first converted to TOA and then cross-calibrated to Landsat equivalent bands (see radiometry section 4.2 ). Then a $\mathrm{L} 7$ scene was resampled to $56 \mathrm{~m}$ and stacked with a time-coincident AWiFS scene of a phase one study area (path 41 row 29). Subsequent evaluation of the simulated Landsat Bands 1 and 7 with the actual Landsat bands yielded a $R^{2}>90 \%$ in all three study areas examined. The explained variance $\left(R^{2}\right)$ for the simulated Landsat Band 6 (TIR), used in the VCT for cloud screening was $\sim 60 \%$.

\subsubsection{VCT processing}

For the Minnesota and Idaho sites, the boundary of the AWiFS image exceeded the boundaries of the TM stack and the AWiFS images were clipped manually, while the North Carolina scene footprint required the TM images to be clipped to the AWiFS boundary. After the clipping step, the VCT was first run on the full TM stack, and then was rerun with the AWiFS image substituted for the corresponding year of TM image. While the AWiFS image and the matching TM scene were both acquired during the growing season of the same year, the image dates were not coincident. The resulting maps were visually assessed and compared to the reference data which was collected using the design-based approach detailed in Thomas et al. (2011).

\subsubsection{Results}

The NAFD mapping techniques using existing Landsat data stacks on average have an overall accuracy of $>80 \%$. Visual comparison of results from the TOA LTSS disturbance year maps show a close match between the full TM stack and that with AWiFS imagery substituted for a single date. For each of these sites, the majority of stand-clearing disturbances are captured successfully with both data stacks (Figs. 16 and 17).

Error matrix results aggregated into 4 classes (persistent nonforest, persistent forest, pre-series disturbance, and disturbed forest) show strikingly similar accuracy between the full TM and AWiFSsubstitution stacks (Table 6). See Thomas et al. (2011) for a thorough description of the reference data collection and validation methodology used in this analysis. However, examination of the full individual year error matrices (Table 7) reveal some differences in mapped results, most prevalent in the Idaho site (path 42 row 29).

Forest disturbances are captured in both instances, but some disturbances are attributed to the incorrect year (2007 rather than 2006) using the AWiFS image. Visual examination of the Idaho time series stacks in conjunction with Google Earth high-resolution imagery reveals that much of the difference in the disturbance year maps stems from different image acquisition dates in 2006: the AWiFS scene was imaged on June 22, while the matching TM scene acquisition date is August 5. For example, snow cover in higher elevations

\footnotetext{
${ }^{2}$ A stepwise multivariate regression was used to simulate Landsat Band 1 and Landsat Band 7, based on AWiFS Bands 2, 3, 4 and 5. AWiFS Bands 2, 3 and 4 were used to simulate a Landsat Band 1 while AWiFS Bands 3, 4 and 5 were used to simulate a Landsat Band 7. Landsat Band 6 was then simulated with stepwise multivariate regression using the newly simulated Landsat Bands 1 and 6, AWIFS Band 3, as well as a shortwave albedo term (Liang, 2001).
} 


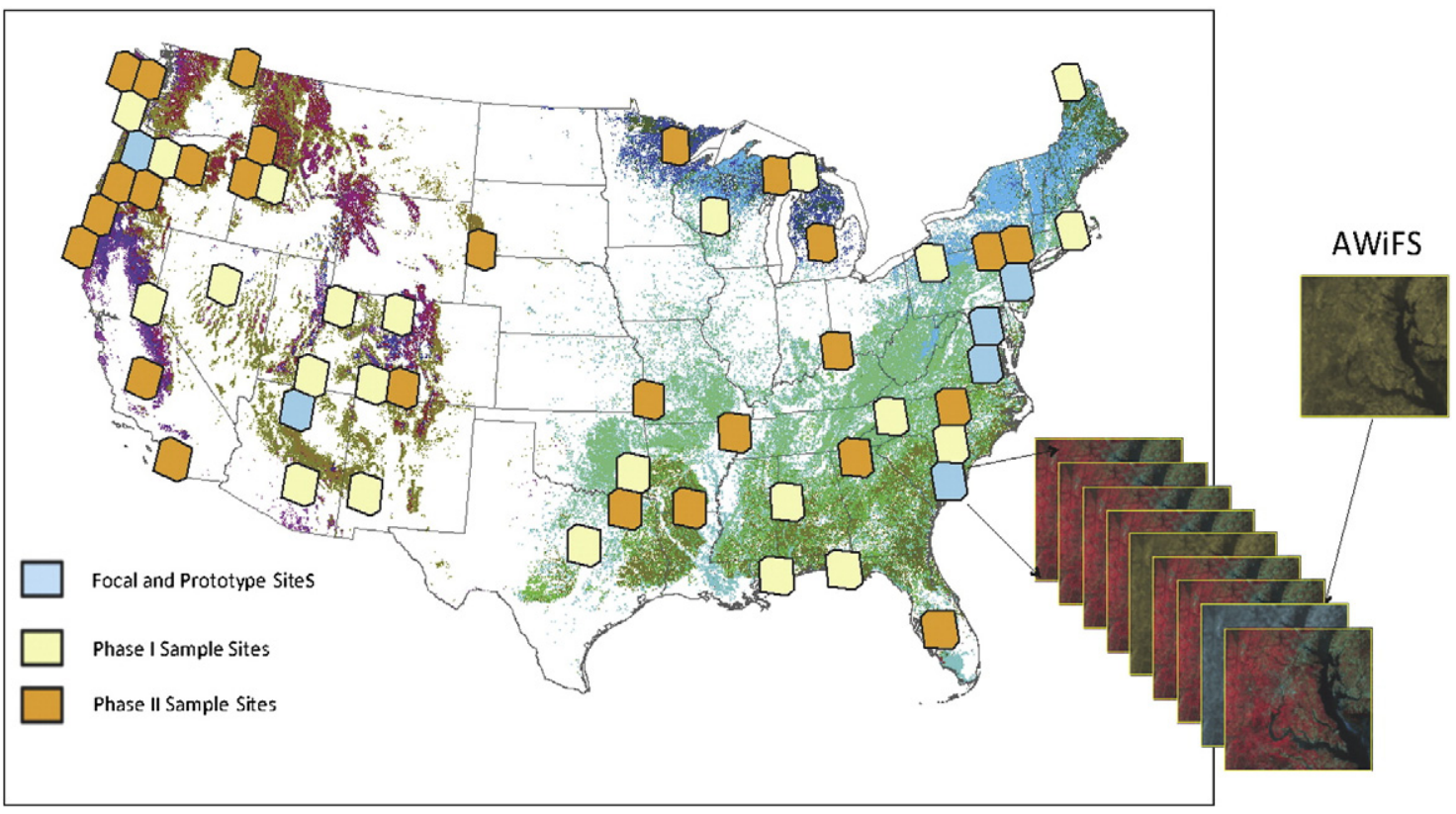

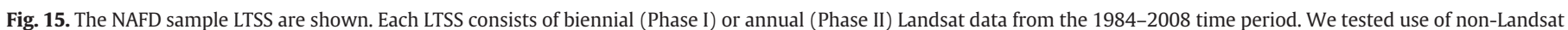
data in creating LCLUC products by substituting AWiFS for matching Landsat data within available LTSS and comparing output disturbance maps.

on June 22 had melted by August 5. A disturbed forest patch can also be visually identified as having been harvested prior to August 5 but after June 22 and thus is not detected by the AWiFS included dataset.

Additionally, a fire that occurred between 2004 and 2006 was correctly identified by the TM data stack but was partially mislabeled as occurring in 2007 in the AWiFS substitution stack (Fig. 17). We suspect that the lack of a "real" SWIR2 Band 7 in AWiFS may impede the detection of fire scars. However, much of the burn scar in this example is captured by AWiFS, so the impact of a simulated Landsat Band 7 on burn area detection must be examined with additional fire areas and a variety of forest types and disturbance regimes in order to be better characterized.
Minor discrepancies between the differing maps exist in all the sites. Visual assessment has detected mislabeled change pixels in the AWiFS substitution relating to minor misregistration and a larger pixel size, observed in the North Carolina (path 16 row 35) site, particularly in heterogeneous areas with small agricultural fields interspersed with suburban homes. Smaller patch sizes and narrow linear features will not be mapped as accurately at the AWiFS scale. Additional variation in the output maps is due to cloud cover in one image and not the other. In some cases, the AWiFS substitution can perform better, if that image has a clear view where the corresponding TM pixel is cloudy. Overall, the results derived with or without the AWiFS images are quite similar (Figs. 16 and 17).

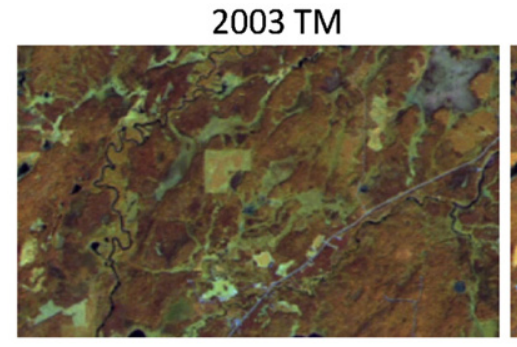

Disturbance Map: TM input

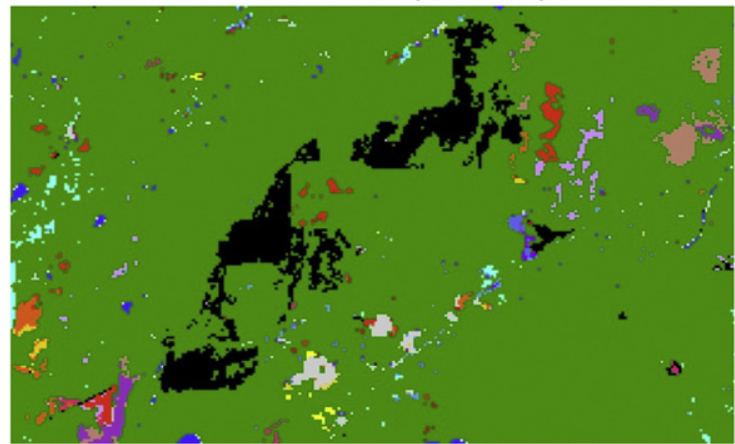

2005 TM

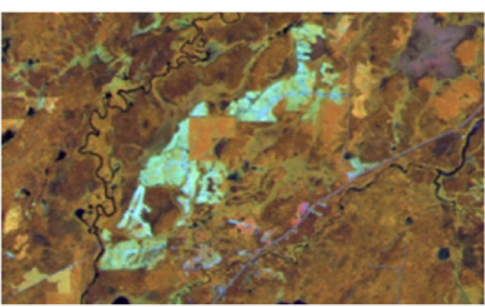

Disturbance Map: AWiFS substitution

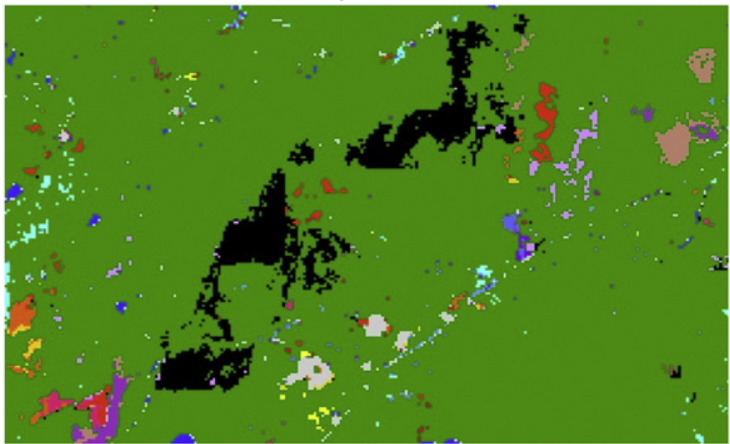

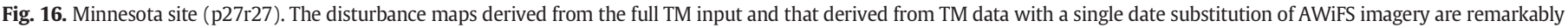

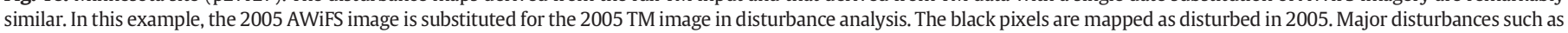
the event shown here are successfully captured in both maps. Satellite imagery is shown in band NIR, SWIR, and R combination. 
Disturbance Map: TM input

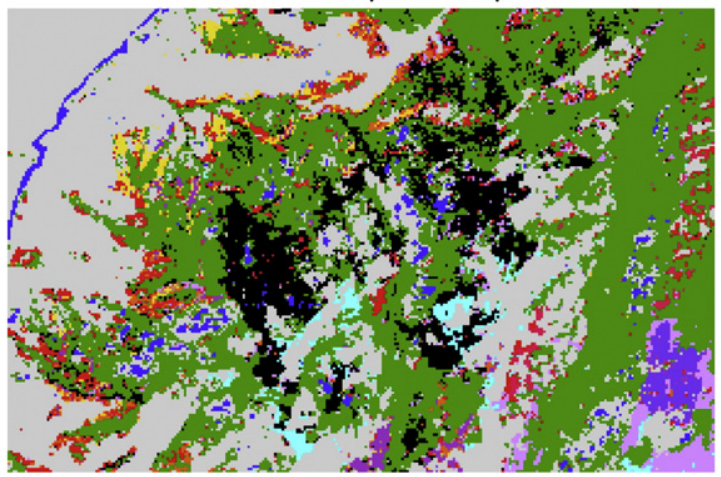

2006 TM

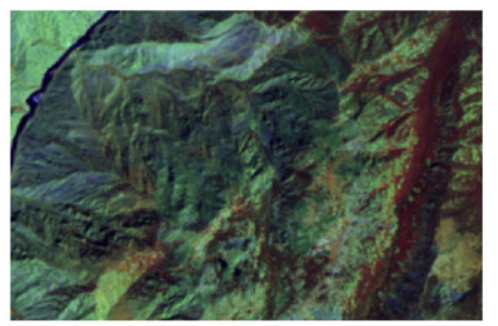

2006 AWiFS

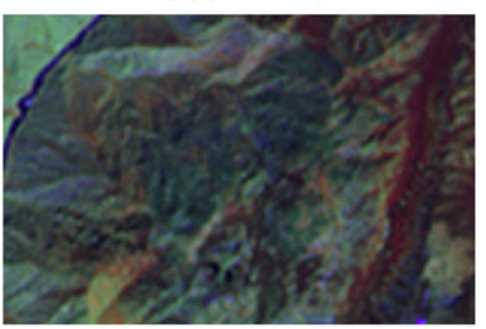

Disturbance Map: AWiFS substitution

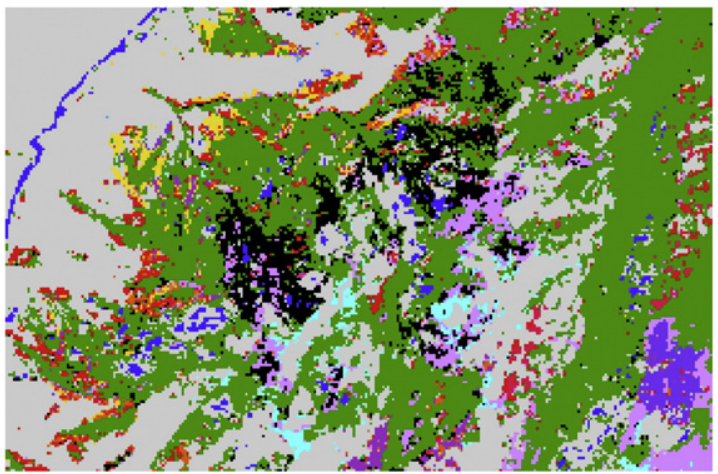

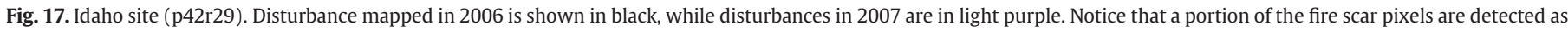
disturbed in the following year with the AWiFS map, although much of the fire scar is mapped correctly.

Results suggest that we can successfully incorporate a single AWiFS scene into existing NAFD data stacks with little or no effect on the overall accuracy of the general LCLUC analyses. However, there appears to be some impact on the results for the disturbance analyses, which in general only impact $1-2 \%$ of the forested regions in any given year. The effects of IFOV, BRDF, and radiometric

Table 6

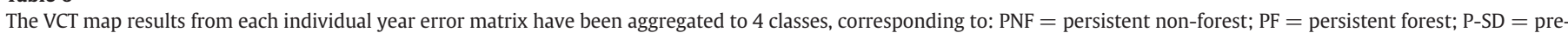

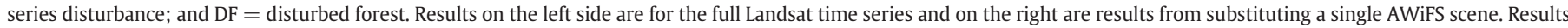
are nearly identical with a single date AWiFS substitution as with all Landsat images.

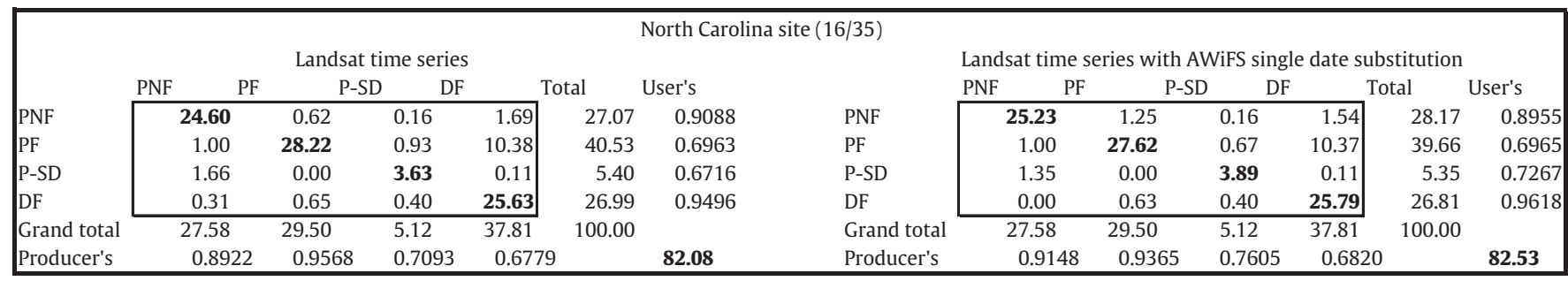

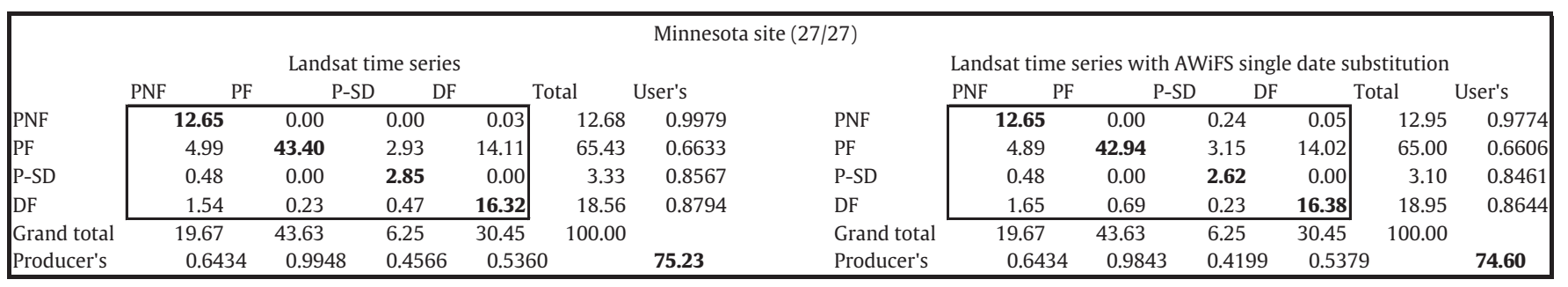

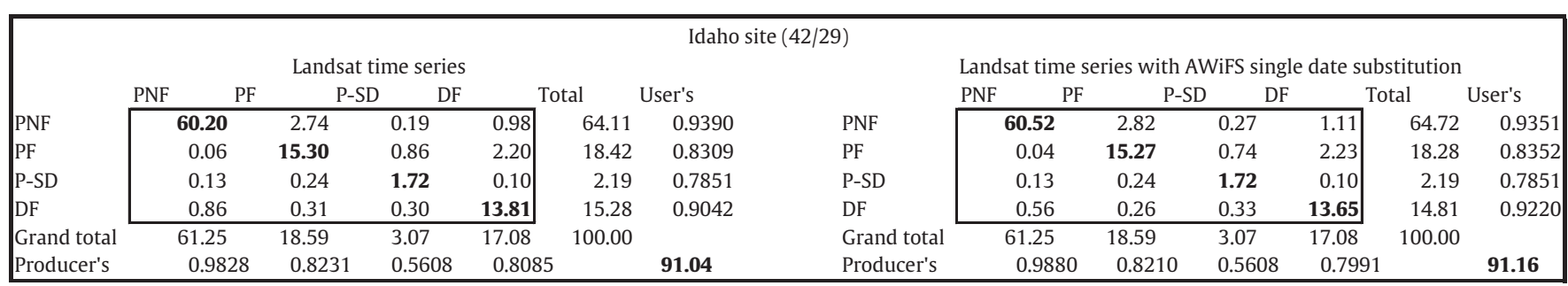


Table 7

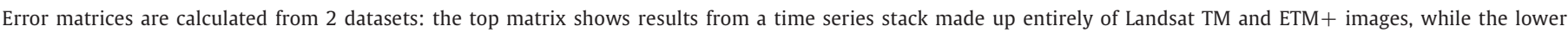

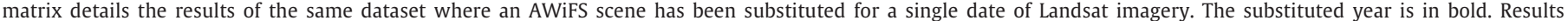

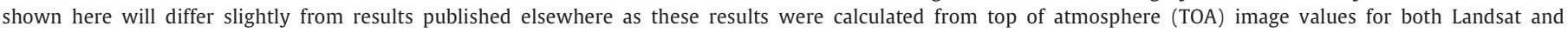
AWiFS scenes. Other published NAFD results are from images converted to surface reflectance.

\begin{tabular}{|c|c|c|c|c|c|c|c|c|c|c|c|c|c|c|c|c|c|}
\hline \multirow[t]{2}{*}{ Sum of map proportion } & \multicolumn{17}{|c|}{ ts_recode } \\
\hline & 1 & 2 & 14 & 1986 & 1988 & 1990 & 1992 & 1994 & 1996 & 1998 & 2000 & 2002 & 2004 & 2006 & 2007 & Grand total & User's \\
\hline \multicolumn{18}{|l|}{ Noawifs_rc } \\
\hline 1 & 60.20 & 2.74 & 0.19 & 0.06 & 0.37 & 0.45 & & & 0.06 & 0.03 & & & & & & 64.11 & 93.90 \\
\hline 2 & 0.06 & 15.30 & 0.86 & 0.32 & 0.43 & 0.48 & 0.13 & & 0.06 & & & 0.13 & 0.20 & 0.27 & 0.19 & 18.42 & 83.09 \\
\hline 14 & 0.13 & 0.24 & 1.72 & & & & & & 0.08 & & & & 0.02 & & & 2.19 & 78.51 \\
\hline 1986 & & & & 0.53 & & & & & & & & & & & & 0.53 & 100.00 \\
\hline 1988 & & 0.08 & & 0.06 & 0.93 & & & & & & & & & & & 1.08 & 86.62 \\
\hline 1990 & 0.07 & & & & 0.08 & 1.09 & & & & & & & & & & 1.23 & 88.22 \\
\hline 1992 & 0.05 & & & & & 0.05 & 0.86 & & & & & & & & & 0.95 & 90.06 \\
\hline 1994 & & & & 0.02 & 0.08 & & 0.05 & 0.62 & & & & & & & & 0.76 & 80.81 \\
\hline 1996 & 0.05 & 0.03 & & 0.06 & & 0.05 & & & 1.81 & 0.03 & & & & & & 2.05 & 88.53 \\
\hline 1998 & 0.07 & & & 0.04 & & & & & 0.07 & 1.03 & & & & & & 1.21 & 85.27 \\
\hline 2000 & 0.59 & 0.06 & & 0.03 & & 0.12 & 0.06 & & 0.17 & 0.10 & 1.81 & & & & 0.08 & 3.01 & 60.00 \\
\hline 2002 & 0.03 & 0.06 & 0.05 & 0.05 & 0.02 & & 0.06 & & & & 0.11 & 0.87 & & & & 1.24 & 69.84 \\
\hline 2004 & & & 0.02 & & & & & & & & & & 0.49 & & & 0.51 & 96.09 \\
\hline 2006 & & & & & & & & & & & & & 0.01 & 1.24 & & 1.26 & 98.84 \\
\hline 2007 & & 0.08 & 0.23 & & & & & & 0.08 & & & & & & 1.06 & 1.44 & 73.44 \\
\hline Grand total & 61.25 & 18.59 & 3.07 & 1.17 & 1.92 & 2.24 & 1.15 & 0.62 & 2.32 & 1.20 & 1.92 & 0.99 & 0.72 & 1.51 & 1.32 & 100 & \\
\hline Producer's & 98.28 & 82.31 & 56.08 & 45.53 & 48.64 & 48.55 & 74.70 & 100.00 & 78.33 & 85.53 & 94.03 & 87.42 & 67.58 & 82.11 & 80.19 & 89.56 & \\
\hline \multicolumn{18}{|l|}{ Awifs_rc } \\
\hline 1 & 60.52 & 2.82 & 0.27 & 0.10 & 0.43 & 0.42 & & & 0.06 & 0.07 & & & 0.02 & & & 64.72 & 93.51 \\
\hline 2 & 0.04 & 15.27 & 0.74 & 0.32 & 0.43 & 0.48 & 0.13 & & & & & 0.10 & 0.25 & 0.33 & 0.19 & 18.28 & 83.52 \\
\hline 14 & 0.13 & 0.24 & 1.72 & & & & & & 0.08 & & & & 0.02 & & & 2.19 & 78.51 \\
\hline 1986 & & 0.04 & & 0.55 & & & & & & & & & & & & 0.59 & 93.55 \\
\hline 1988 & & & 0.11 & 0.04 & 0.87 & & & & & & & & & & & 1.02 & 85.43 \\
\hline 1990 & 0.07 & & & & 0.08 & 1.12 & & & & & & & & & & 1.26 & 88.48 \\
\hline 1992 & 0.07 & & & & & 0.05 & 0.85 & & & & & & & & & 0.97 & 88.08 \\
\hline 1994 & & & & 0.02 & 0.08 & & 0.05 & 0.62 & & & & & & & & 0.76 & 80.81 \\
\hline 1996 & 0.08 & 0.03 & & 0.06 & & 0.05 & & & 1.81 & 0.03 & & & & & & 2.07 & 87.57 \\
\hline 1998 & 0.07 & & & 0.04 & & & & & 0.07 & 1.03 & & & & & & 1.21 & 85.27 \\
\hline 2000 & 0.59 & 0.06 & & & & 0.12 & 0.06 & & 0.22 & 0.07 & 1.81 & & & & 0.08 & 2.66 & 68.00 \\
\hline 2002 & 0.03 & 0.06 & 0.05 & 0.05 & 0.02 & & 0.06 & & & & 0.11 & 0.89 & & & & 1.27 & 70.38 \\
\hline 2004 & & & 0.02 & & & & & & & & & & 0.40 & & & 0.42 & 95.25 \\
\hline 2006 & & & & & & & & & & & & & 0.01 & 0.82 & & 0.83 & 98.25 \\
\hline 2007 & & 0.08 & 0.15 & & & & & & 0.08 & & & & 0.02 & 0.37 & 1.06 & 1.75 & 60.64 \\
\hline Grand total & 61.25 & 18.59 & 3.07 & 1.17 & 1.92 & 2.24 & 1.15 & 0.62 & 2.32 & 1.20 & 1.92 & 0.99 & 0.72 & 1.51 & 1.32 & 100 & \\
\hline Producer's & 98.80 & 82.10 & 56.08 & 47.29 & 45.45 & 49.79 & 74.45 & 100.00 & 78.33 & 85.53 & 94.03 & 89.69 & 55.16 & 54.10 & 80.19 & 89.34 & \\
\hline
\end{tabular}

calibration as well as cloud cover variations are not as yet fully examined as other sources of error remain to be understood. Additionally, use of more than one AWiFS scene in a time series data stack has yet to be tested.

\section{Summary and conclusions}

This analysis once again demonstrates the importance of aggressive and continued assessments of imaging systems that are planned for use in monitoring the Earth's state and dynamics. Although the AWiFS and Landsat TM sensors nominally evaluate equivalent portions of the electromagnetic spectrum at similar times of day, because of the way these sensors were designed and operated they produce somewhat different records of the same land surface spectral phenomena.

\subsection{Compatibility of Landsat to AWiFS}

Our technical inspection of the AWiFS sensor versus the Landsat Thematic Mapper (both L5 TM and L7 ETM+) reveals considerable differences in the configuration and functioning of these two land imaging systems. The largest differences are in sensor spectral configuration and the area imaged by each system. These differences in turn, could lead to substantial differences in the image data produced by each observatory. In comparing the imagery from the two sensor systems, we have found in general that the VNIR observations (B2-B4) are quite comparable between the two systems. On the other hand, the change in detector size and therefore camera configuration in the SWIR region (B5) appears to create problems with band-to-band registration between the VNIR and SWIR pixels particularly nearer the edges of the AWiFS subimages. Work carried by GeoEye suggested that this SWIR issue might be easily resolved through use of non-linear regression methods. Within the context of this study we did not pursue this possibility.

In general, the radiometric properties of the two systems appear quite compatible although the radiance values, based on AWiFS preflight calibration information appear general to measure lower atsensor spectral radiances and/or TOA reflectance than L5 TM and L7 $\mathrm{ETM}+$. One possibility is that sensor degradation has taken place for AWiFS since launch, which is often encountered with optical sensors. A first examination of this possibility does reveal a potential decline in sensor radiometric sensitivity. Neither resources nor access to sufficient AWiFS observations was available to fully evaluate this possibility.

An initial concern was that because of the relatively large swath width $\left( \pm 24.3^{\circ}\right)$ of the AWiFS sensor the impact of BRDF would be significant in these observations. The worst of the effects occurs when a sensor images within $\pm 10^{\circ}$ of the principal plane of the sun. For AWiFS, this occurs nearer to the equator, so that the midlatitude observations evaluated here are less impacted. Nevertheless, we do observe potentially significant BRDF effects that should be considered when carrying out analyses with AWiFS observations.

Despite these observatory differences, when the AWiFS are used in place of Landsat observations in agricultural and forest applications, 
the resultant analyses are not substantially different. Indeed the major differences are observed in distinguishing localized phenomena such as forest disturbance and crop changes from year to year. However statistical inferences and significance levels could be impacted by switching between these systems.

Finally, much of what has been revealed in this study suggests the need for more thorough and ongoing assessments of AWiFS as well as the Landsat TM observatories. Certainly what has been learned from the 39+ year history of the Landsat observatory is that continued assessment of sensor radiometry and geometry are vital for high quality scientific and applied uses of these remotely sensed data. This study can only be considered the beginning of such an analysis for the AWiFS sensor, particularly considering that a new AWiFS sensor has been put into orbit on ResourceSat-2.

\subsection{Toward an international global land observatory}

One of the most difficult aspects of this study has been gaining adequate access to the AWiFS observations needed to conduct this research. Without the continued effort of the US Department of Agriculture to gain access to at least some of these observations for their purposes, execution of this study would not have been possible. However, there are several examples, including long-term radiometric calibration, where our efforts have been constrained by limited access to these observations. There is some hope that with the launch of ResourceSat-2 that the data access policies will be changed to better address the expectations of the CEOS Moderate Resolution Land Constellation. Basic access to the data is fundamental toward moving forward with the CEOS strategy. The same can be said of all such similar systems from Europe (Sentinel 2), China (HJ series) and others.

A second major step that must be taken, for the Moderate Resolution Land Constellation to become a reality contributing to international understanding, is that resources must be applied to continue the study of how to calibrate and merge imaging data from disparate and complex imaging systems. There does appear to be promise in using sensors such as Landsat and AWiFS in a complementary way. This will only be effectively accomplished if a detailed understanding of how to bring this data set into complementary agreement is developed.

\section{Acknowledgments}

This work was supported by the NASA Land-Cover and Land-Use Change (LCLUC) Grant NNX09AR41G (Pagnutti and Ryan). The SGT, Inc., work (Chander) was performed under the US Geological Survey contract 08HQCN0005. Any use of trade, product, or firm names is for descriptive purposes only and does not imply endorsement by the US Government. The UMD work (Goward, Marx and Thomas) was supported under NASA grants NNX09AV47G (Land Use and Land Cover) and NNG05GE55G (Applied Sciences). The support of the USDA Data Archive is much appreciated in accessing the AWiFS imagery.

\section{References}

Angal, A., Xiong, X., Choi, T., Chander, G., \& Wu, A. S. (2010). The Sonoran and Libyan Desert test sites to monitor the temporal stability of reflective solar bands for Landsat 7 Enhanced Thematic Mapper plus and Terra Moderate Resolution Imaging Spectroradiometer sensors. Journal of Applied Remote Sensing, 4.

Boryan, C., \& Craig, M. (2005). Multiresolution Landsat TM and AWiFS imagery sensor assessment for crop area estimation in Nebraska. Pecora, 16, Sioux Falls, SD: American Society of Photogrammetry and Remote Sensing (pp. unpaginated CD-ROM).

Chander, G., Coan, M. J., \& Scaramuzza, P. L. (2008). Evaluation and comparison of the IRS-P6 and the Landsat sensors. IEEE Transactions on Geoscience and Remote Sensing, 46, 209-221.

Chander, G., Markham, B. L., \& Helder, D. L. (2009). Summary of current radiometric calibration coefficients for Landsat MSS, TM, ETM+, and EO-1 ALI sensors. Remote Sensing of Environment, 113, 893-903.
Chander, G., \& Stensaas, G. L. (2008). Evaluation of candidate Landsat data gap sensors. International geoscience and remote sensing symposium (IGARSS). Boston, Massachusetts: IEEE.

Chander, G., Xiong, X., Choi, T., \& Angal, A. (2010). Monitoring on-orbit calibration stability of the Terra MODIS and Landsat 7 ETM + sensors using pseudo-invariant test sites. Remote Sensing of Environment, 114, 925-939.

Danaher, T. J. (2002). An empirical BRDF correction for Landsat TM and ETM + imagery. 11th Australasian Remote Sensing and Photogrammetry Conference (pp. 2654-2657).

Danaher, T. J., Wu, X., \& Campbell, N. A. (2001). Bi-directional reflectance distribution function approaches to radiometric calibration of Landsat ETM + imagery. IEEE 2001 international geoscience and remote sensing symposium (pp. 3654-3657). : IEEE.

Dave, H., Dewan, C., Paul, S., Sarkar, S., Pandya, H., Joshi, S., et al. (2006). AWiFS camera for Resourcesat. Proceedings SPIE, 6405, 64050X. http://dx.doi.org/10.1117/12.693971.

Goward, S. N., Arvidson, T. A., Williams, D. L., \& Irons, J. (2011). The future of Landsat-class high resolution optical multispectral remote sensing. In B. Ramachandran, C. Justice, \& M. Abrams (Eds.), Land remote sensing and global environmental change: NASA's earth observing system and the science of ASTER and MODIS (pp. 809-834). New York: Springer.

Goward, S. N., Masek, J. G., Cohen, W., Moisen, G., Collatz, G. J., Healey, S., et al. (2008) Forest disturbance and North American carbon flux. Eos Transactions, 89, 105-116.

Goward, S. N., Williams, D. L., Arvidson, T. A., Irons, J., \& Irish, R. R. (2009). Moderate spatial resolution optical sensors. In T. Warner, D. N. Nellis, \& G. Foody (Eds.), SAGE handbook of remote sensing (pp. 123-138). London, U.K.: Sage.

Gutman, G. (1998). Monitoring global vegetation using AVHRR. IEEE international geoscience and remote sensing symposium (pp. 5:509-2511. Seattle, WA).

Gutman, G. G., Byrnes, R., Masek, J., Covington, S., Justice, C., Franks, S., et al. (2008). Towards monitoring land-cover and land-use changes at a global scale: The global land survey 2005. Photogrammetric Engineering and Remote Sensing, 74, 6-10.

Gutman, G., Tarpley, D., Ignatov, A., \& Olson, S. (1995). The enhanced NOAA global land dataset from the advanced very high resolution radiometer. Bulletin of the American Meteorological Society, 76, 1141-1156.

Huang, C., Goward, S. N., Masek, J. G., Gao, F., Vermote, E. F., Thomas, N., et al. (2009). Development of time series stacks of Landsat images for reconstructing forest disturbance history. International Journal of Digital Earth, 2, 195-218.

Huang, C., Goward, S. N., Masek, J. G., Thomas, N., Zhu, Z., \& Vogelmann, J. E. (2010). An automated approach for reconstructing recent forest disturbance history using dense Landsat time series stacks. Remote Sensing of Environment, 114, 183-198.

Johnson, D. M. (2008). A comparison of coincident Landsat 5 TM and Resourcesat-1 AWiFS imagery for classifying croplands. Photogrammetric Engineering and Remote Sensing, 74, 1413-1423.

Lee, D. S., Storey, J. C., Choate, M. J., \& Hayes, R. W. (2004). Four years of Landsat-7 on-orbit geometric calibration and performance. IEEE Transactions on Geoscience and Remote Sensing, 42, 2786-2795.

Liang, S. (2001). Narrowband to broadband conversions of land surface albedo I: Algorithms. Remote Sensing of Environment, 76, 213-238.

Liang, S., \& Strahler, A. H. (1994). Retrieval of surface BRDF from multiangle remotely sensed data. Remote Sensing of Environment, 50, 18-30.

Los, S. O., North, P. R. J., Grey, W. M. F., \& Barnsley, M. J. (2005). A method to convert AVHRR normalized difference vegetation index time series to a standard viewing and illumination geometry. Remote Sensing of Environment, 99, 400-411.

Lucht, W., Schaaf, C. B., \& Strahler, A. H. (2000). An algorithm for the retrieval of albedo from space using semiempirical BRDF models. IEEE Transactions on Geoscience and Remote Sensing, 38, 977-998.

Lutes, J. (2005). RESOURCESAT-1 geometric accuracy assessment. ASPRS 2005 Annual Conference. Baltimore, $M D$.

Lutes, J. (2006). An overview of GeoEye's AWiFS ortho production process. USDA/PECAD Seminar (pp. 33). Washington, D.C.: USDA PECAD.

Markham, B. L., Storey, J. C., Williams, D. L., \& Irons, J. R. (2004). Landsat sensor performance: history and current status. IEEE Transactions on Geoscience and Remote Sensing, 42, 2691-2694.

Masek, J. G., Vermote, E. F., Saleous, N. E., Wolfe, R., Hall, F. G., Huemmrich, K. F., et al (2006). A Landsat surface reflectance dataset for North America, 1990-2000. IEEE Geoscience and Remote Sensing Letters, 3, 68-72.

Mueller, R., \& Seffrin, R. (2006). New methods and satellites: A program update on the NASS cropland data layer acreage program. The International Archives of the Photogrammetry, Remote Sensing and Spatial Information Sciences, 36, 8.

National Remote Sensing Agency (2003). RESOURCESat-1 (IRS-P6) data users handbook. In G.o.I. Department of Space (Ed.), Blanagar, Hyderbad: National Remote Sensing Agency.

Norman, J. M., Welles, J. M., \& Walter, E. A. (1985). Contrasts among bidirectional reflectance of leaves, canopies, and soils. IEEE Transactions on Geoscience and Remote Sensing, GE-23, 659-667.

Storey, J., \& Choate, M. (2000). Landsat 7 on-orbit geometric calibration and performance. Orlando, FL, USA: Society of Photo-Optical Instrumentation Engineers.

Storey, J., Morfitt, R., \& Thorson, P. (1999). Image processing on the Landsat 7 image assessment system. 1999 ASPRS Annual Conference, from Image to Information: ASPRS.

Thomas, N., Huang, C., Goward, S. N., Powell, S., Rishmawi, K., Schleeweis, K., et al. (2011). Validation of North American forest disturbance dynamics derived from Landsat time series stacks. Remote Sensing of Environment, 115, 19-32.

Walthall, C. L., Norman, J. M., Welles, J. M., Campbell, M., \& Blad, B. L. (1985). Simple equation to approximate the bidirectional reflectance from vegetative canopies and bare soil surfaces. Applied Optics, 24, 383-387. 